TAPROBANICA, ISSN 1800-427X. November, 2021. Vol. 10, No. 02: pp. 89-120, pls. 18-25.

C Research Center for Climate Change and Department of Biology, Faculty of Mathematics \& Natural Sciences, University of Indonesia, Depok 16424, INDONESIA.

http://www.taprobanica.org

https://doi.org/10.47605/tapro.v10i2.257

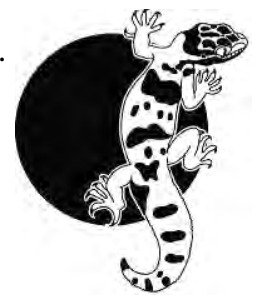

urn:Isid:zoobank.org:pub:608734DC-5D05-4AC6-A6F9-FF2508828D8D

\title{
TAXONOMIC COMPOSITION OF THE Rhabdophis subminiatus (SCHLEGEL, 1837) SPECIES COMPLEX (REPTILIA: NATRICIDAE) WITH THE DESCRIPTION OF A NEW SPECIES FROM CHINA
}

\section{Patrick David $^{1} \&$ Gernot Vogel $^{2^{*}}$}

\author{
${ }^{1}$ Institut de Systématique, Évolution et Biodiversité (ISYEB), Muséum National d'Histoire Naturelle, Sorbonne \\ Université, École Pratique des Hautes Études, Université des Antilles, CNRS, CP 30, 57 rue Cuvier, F-75005 \\ Paris, France; E-mail: patrick.david@mnhn.fr \\ ${ }^{2}$ Society for Southeast Asian Herpetology, Im Sand 3, D-69115 Heidelberg, Germany \\ *Corresponding author. E-mail: gernot.vogel@t-online.de
}

\begin{abstract}
The systematics of Rhabdophis subminiatus (Schlegel, 1837) at subspecies level has long proved to be controversial. We analyse the variation of selected morphological characters in 179 specimens from populations covering the whole range of $R$. subminiatus sensu lato. Based on this review, we recognize four morphological groups, of which two do not agree with the current definitions and distributions of the currently recognized subspecies $R$. s. subminiatus. The "northernmost group" agrees with the definition of Natrix helleri Schmidt, 1925. In contrast, the "southernmost group" agrees with the syntypes of Tropidonotus subminiatus and we here restrict this species to the Sunda Region. We also discuss a previous designation of the lectotype of $T$. subminiatus, which we consider invalid, and we here make it valid in the sense of the Code. Furthermore, our analysis allows us to define a third group that is widespread in the Indochinese Region and Malayan Peninsula. For this geographically "central group", the name Natrix subminiata siamensis Mell, 1931, is available. We therefore resurrect this taxon from its synonymy with $R$. subminiatus and we designate a lectotype in agreement with requirements of the Code. Lastly, we recognize a fourth group at species level, endemic to Hainan Island, China, that we describe as a new species. This division into four morphological groups at species level is coherent with phylogenetic analyses recently published in the literature. We also discuss and modify the taxonomic status of Natrix subminiata hongkongensis Mell, 1931 and Natrix (Rhabdophis) laobaoensis Bourret, 1934, now regarded as synonyms of $R$. subminiatus and $R$. siamensis, respectively.
\end{abstract}

Key words: Asia, Hainan, lectotype, morphological variation, Natricidae, Natrix, Serpentes, taxonomy 


\section{Introduction}

The natricid species Rhabdophis subminiatus (Schlegel, 1837), as conceived in the literature, is widely distributed in tropical and subtropical Asia, from Northeast India to southern China, and across the Indochinese Peninsula, southwards into Thailand and West Malaysia and on to Java Island in Indonesia (Dunn 1927, Smith 1943, Das 2010, Wallach et al. 2014). It is not rare in many areas and is popularly known as the "Red-necked keelback". Schlegel (1837: 313) described this species, as Tropidonotus subminiatus, based on four primary syntypes deposited in the Nationaal Natuurhistorisch Museum (Naturalis), Leiden, the Netherlands, all originating from the island of Java, and one secondary syntype with an erroneous locality "Guinea"-see the species account. Fitzinger (1843: 27) placed this species in the new genus Rhabdophis. Subsequently, it was referred to the genera: Amphiesma Duméril, Bibron \& Duméril, by Duméril et al. (1854), Tropidonotus F. Boie, e.g. by Günther (1858) and Boulenger (1893a), and Natrix Laurenti by Barbour (1912), Mell (1931), Pope (1935), Smith (1943) and others. However, Wall (1923) and Bourret (1936) referred this species to Rhabdophis, a genus of which Malnate (1960) eventually confirmed the validity. After him, most subsequent authors used the combination Rhabdophis subminiatus.

Barbour (1912; as Natrix subminiata) was the first author to discuss the potential taxonomic division of $R$. subminiatus when he suggested the existence of geographic races, i.e. subspecies, within this species. He summarized the variation in the number of ventral plates from various populations based on examining a large number of specimens and data from the literature. Barbour (1912) showed that these differences defined four groups: (1) populations from Java; (2) populations from "Tenasserim, Siam, Lao Mountains and Cambodia", based on the values given by Boulenger (1893a); (3) population from Hong Kong, also based on Boulenger (1893a); and (4) populations from India and central Myanmar. Barbour (1912) also mentioned a specimen from Sulawesi, described as Tropidonotus manadensis Günther, 1873 but did not consider it distinct from "Natrix subminiata". Nevertheless, Barbour (1912) did not define any subspecies.

Schmidt (1925) described Natrix helleri (Type locality: "Tengyueh, 5500 feet altitude, Province of Yunnan, China"; now Tengchong, $25^{\circ} 01^{\prime} \mathrm{N}, 98^{\circ} 30^{\prime} \mathrm{E}$, Province of Yunnan, People's
Republic of China). Mell (1931) considered this taxon a subspecies of Natrix subminiata and it was regarded as such, in the genera Natrix or Rhabdophis, by all subsequent authors, e.g. Pope (1935), Bourret (1936), Rendahl (1937), Smith (1943), Taylor \& Elbel (1958), Taylor (1965) and Das (2010). Mell (1931: 203) also briefly described Natrix subminiata hongkongensis (type locality: "Hong Kong") and Natrix subminiata siamensis (type localities: "Siam", now Thailand and "Hainan"; now Hainan Island, China), based on their number of ventral scales. Pope (1935) considered both taxa to be synonyms of Natrix subminiata subminiata.

The definition and ranges of the subspecies of $R$. subminiatus subsequently proved to be quite controversial. Following Pope (1935) and Smith (1943), as Natrix subminiata in both cases, or Bourret (1936) in the genus Rhabdophis, R. subminiatus was constantly divided in the literature into two subspecies, $R$. $s$. subminiatus and $R$. s. helleri. This arrangement is still widely used in the literature (see, e.g. Das 2010). However, the range of the subspecies has been controversial, as discussed below. Most recent authors followed Smith (1943) who placed all populations into the subspecies $R$. $S$. subminiatus except the northernmost ones, north of latitude $22^{\circ} \mathrm{N}$, which were referred to $R$. s. helleri.

In discussing the systematics of Natrix subminiata, Pope (1935) rightly stated that "This question cannot be settled until a careful study of good series from Indo-China, Siam and Burma can be made." In order to solve the status of the subspecies of $R$. subminiatus and their respective ranges, we examined morphological variation in specimens originating from populations covering the whole range of the species. We also examined syntypes of Natrix subminiata siamensis. We also discuss in detail below the validity of the taxa hongkongensis and siamensis under the accounts of Rhabdophis subminiatus and $R$. siamensis, respectively. Our data clearly suggest a more complex taxonomy than previously accepted. We propose here a new taxonomic scheme in which we distinguish four geographically separated populations here defined at species level.

\section{Material and methods}

Our revision is based on external morphological characters regarded as taxonomically significant in the genus Rhabdophis as defined by Malnate (1960) and for other Asian members of the 
family Natricidae by David et al. (2015a-b). We also investigated the dentition of representative specimens of the various populations. A total of 179 specimens of the complex of $R$. subminiatus were examined. These specimens are listed in the Appendix. Furthermore, we compared our morphological results with the molecular phylogenies published by Takeuchi et al. (2018) and Liu et al. (2021); we discuss the comparisons below; see the Discussion.

Morphological characters: Maxillary teeth were counted by removing the exterior gingiva of the right jaw in situ in adult preserved specimens only; tooth sockets were included in the counts in cases of tooth loss. Measurements, except snout-vent and tail lengths, were taken with a slide-calliper to the nearest $0.1 \mathrm{~mm}$; snout-vent and tail lengths were measured to the nearest millimeter. The number of ventral plates is counted according to Dowling (1951). The numbers of dorsal scale rows are given at one head length behind head, at midbody (i.e. at the level of half of the snout-vent length), and at one head length before vent respectively. The terminal pointed scute is not included in the number of subcaudals. Values for symmetric head characters are given in left/right order. A total of 72 morphometric and morphological characters bearing on the scalation and patterns of the dorsum, venter and especially of the head, were recorded for each specimen.

Abbreviations (Measurements and ratios): HL, head length (from the tip of the snout to the angle of the jaws); SVL, snout-vent length (from the tip of the snout to the vent); TaL, tail length; TL, total length; TaL/TL, ratio tail length/total length. (Meristic characters): DSR, formula of dorsal scale rows reduction; IL, infralabials (number of infralabial scales); SC, subcaudals (number of subcaudal scales); SL, supralabials (number of supralabial scales); VEN, ventrals (number of ventral plates).

Univariate analyses: The analyses of morphological data were based on comparisons of statistical values (mean value and standard deviation). A test of Mann-Whitney or "U test" (see Siegel 1956) was applied as necessary. Abbreviations: $n$, number of specimens; $x$, mean value; $s d$, standard deviation; $P$, probability of occurrence of a value as extreme as or more extreme than the observed value; $U$, the statistics in the Mann-Whitney test.

Museum abbreviations: NHMUK, Natural History Museum, London, UK; FMNH, Field
Museum of Natural History, Chicago, USA; HT, Departmental Museum of Zoology, Mizoram University, Laboratory of Hmar Tlawmte Lalremsanga, Aizawl, India; MNHN-RA, Muséum National d'Histoire Naturelle, Paris, France; NMW, Naturhistorisches Museum Wien, Vienna, Austria; RMNH, Nationaal Natuurhistorisch Museum (Naturalis), Leiden, the Netherlands; ZFMK, Zoologisches Forschungsinstitut und Museum Alexander Koenig, Bonn, Germany; ZMB, Zoologisches Museum für Naturkunde der HumboldtUniversität zu Berlin, Berlin, Germany.

\section{Results}

All examined specimens share the following characters, typical of the genus Rhabdophis as defined by Malnate (1960) and Malnate \& Underwood (1988), namely: (1) maxillary teeth 19-24 + 2-3 separated posterior maxillary teeth abruptly and strongly enlarged, (2) 19 dorsal scale rows at midbody, (3) eye large with round pupil, (4) cloacal plate divided, (5) head distinct from the neck, (6) nostrils lateral, (7) arrangement of head scales complete, and (8) internasals broadly truncated anteriorly.

The analysis of morphological characters of examined specimens showed that not all proved to be useful in our analyses. For example, the number of maxillary teeth is relatively constant among all specimens and we will not further consider this character. Other characters, such as the relative length of the tail, and the number of subcaudals according to sex showed too much overlap among populations to be taxonomically significant. Eventually, we identified only seven unrelated characters belonging to morphology, scalation, and dorsal, ventral and head colour patterns that allowed us to define four informal groups of specimens. Based on these seven characters, we define four morphological groups as presented in Table 1. The seven characters (A to $\mathrm{G}$ below) considered diagnostic are as follows (Figs. 1-8):

\section{(A). Presence of a nuchal groove:}

(A1). Specimens with no nuchal groove (exceptionally a shallow groove barely visible): group 1

(A2). Specimens with a moderate to strong nuchal groove: group $2+$ group $3+$ group 4

\section{(B). Enlarged, paired nuchal scales:}

(B1). Specimens with no enlarged (exceptionally slightly enlarged) nuchal scales: group 1 . 
(B2). Specimens with 2-8 enlarged, paired and aligned nuchal scales: group $2+$ group $3+$ group 4

(C). Number of ventral plates:

(C1). Specimens with no more than 158 VEN

(C1.a). Specimens with 132-145 VEN: group 1

(C1.b). Specimens with 137-158 VEN: group $2+$ group 4

(C2). Specimens with 157-178 VEN: group 3

(D). Position of the dorsal reduction from 19 to 17 DSR, expressed in the number of ventral plates:

(D1). Position of the reduction below the $76^{\text {th }}$ VEN: group 1

(D2). Position of the reduction at least on the $75^{\text {th }}$ VEN:

(D2.a). Position of the reduction at most on the $84^{\text {th }}$ VEN: group 2

(D2.b). Position of the reduction at least on the $82^{\text {nd }}$ VEN: group 3

This character could unfortunately not be recorded in specimens of group 4.

(E). Pattern of the lateral side of the head:

(E1). Subocular streak not conspicuous:

(E1.a). Subocular streak completely absent: group 4

(E1.b). Subocular streak usually reduced, incomplete or faint, often absent: group 3

(E2). Subocular streak conspicuous:

(E2.a). Streak shaped as a narrow vertical bar or a curved streak directed downwards and forwards: group 1

(E2.b). Streak shaped as broad, solid (rarely faint) triangular fin directed backwards: group 2

(F). Presence of a pale dorsolateral stripe:

(F1). Usually present on $5^{\text {th }}-6^{\text {th }}$ DSR, either complete or reduced to a series of longitudinally aligned rectangular blotches: group 1

(F2). No pale dorsolateral stripe or aligned rectangular blotches: group $2+$ group $3+$ group 4

(G). Pattern of the venter:

(G1). Venter with a uniform pale background colour:

(G1.a). With a dark dot on the tips of each ventral plate (Fig. 1B) (rarely only on the anterior part of the venter): group 1
(G1.b). With no dark dot on the tips of ventrals (or only on the anterior part of the venter): group $2+$ group 4

(G2). Venter heavily powdered with numerous dark dots: group 3

We consider these four groups, fully diagnosable based on their morphological characters, to be taxa distinct at species level. Phylogenies published by Liu et al. (2021) confirm the distinctiveness - see the Discussion. Based on their name-bearing types, we identify these taxa as follows:

Group 1: Rhabdophis subminiatus (Schlegel, 1837) sensu stricto.

Group 2: Rhabdophis siamensis (Mell, 1931) comb. nov.

Group 3: Rhabdophis helleri (Schmidt, 1925) comb. nov.

Group 4: Rhabdophis sp., a new species endemic to Hainan Island described below.

Table 1. Combination of characters defining the four morphological groups recognized in the Rhabdophis subminiatus species complex; ? = not investigated.

Species group \& combination of characters

(1). R. subminiatus

A1, B1, C1.a, D1, E2.a, F1, G1.a

(2). R. siamensis

A2, B2, C1.b, D2.a, E2.b, F2, G1.b

(3). R. helleri

A2, B2, C2, D2.b, E1.b, F2, G2

(4). Rhabdophis sp. nov.

A2, B2, C1.b, D?, E1.a, F2, G1.b

The four species recognized above can be distinguished by a combination of several characters, as noted in Table 1 above. However, one or two of them are usually enough to separate unambiguously the species if the specimen can be examined in its totality, including its venter.

According to our material, we do not here consider the presence of the red area on the upper surface of the neck and anterior part of the body to be a diagnostic character. Whereas the bright vermilion-red colour of the skin between dorsal scales, and the edges of scales themselves, is always present and conspicuous in specimens of groups 1 and 2, although it is sometimes subdued in larger specimens of group 2 or in long-preserved specimens, this red colour is also present in specimens of groups 3 and 4. 
We agree on the fact that this red colour on the neck is sometimes relatively subdued in groups 3 and 4, but it is often largely present on a length of the body greater than in groups 1 and 2, as can be seen in the references cited below in the account of $R$. helleri. We cannot recognize the presence of the red colour on the neck to be a diagnostic character. It should be noted that this red hue turns to pale yellow or cream in longpreserved specimens and can be difficult to distinguish from other pale dorsal markings.

\section{Systematics}

We treat below these four species in the order corresponding to the number of their group. We present their distribution ranges on Figure 9. The localities on the maps are based both on specimens examined by us and on literature records for which the identification is unambiguous, namely only when a record is accompanied by scalation data or a photograph allowing us to identify the specimen.

\section{Rhabdophis subminiatus (Schlegel, 1837)} (Figs. 1, 2, 9; Table 3)

Tropidonotus subminiatus Schlegel, 1826a: 236, 1826b: 291 [nomen nudum, no description] Tropidonotus subminiatus Schlegel, 1837: 313 Tropidonotus manadensis Günther, 1873: 170 Pseudoxenodon intermedius Lönnberg, 1899: 109 Natrix subminiata hongkongensis Mell, 1931: 203

Taxonomic history. Schlegel (1837) described this species based on four primary syntypes, all from "à Java dans les champs de sawa inondés" (flooded paddy fields in Java, Indonesia). These four syntypes are all currently extant (examined by us) in the collections of the Nationaal Natuurhistorisch Museum (Naturalis), in Leiden, the Netherlands, as follows: (1) adult female, RMNH 1061 (2) adult female, RMNH 1063; (3) adult male RMNH 1066; and (4) adult male RMNH 1067; all deposited by C.G.C. Reinwardt (between 1816-1821). However, it has been overlooked in the literature that Schlegel also based his original description on a specimen depicted by Seba (1735: 20; Pl. 19: figures 3 and 4; as "Serpens, elegantissima, ex Guinea" / "Serpent très-beau, de Guinée"). Schlegel clearly mentioned this specimen in his description, and considered it a juvenile of the species, but he did not discuss the erroneous locality given by Seba. Anyway, the specimen, currently untraced, depicted on Seba's plate becomes a secondary syntype of Tropidonotus subminiatus. Unfortunately, Seba's plate does not allow us to refer that specimen to any of the four species treated here.

The potential heterogeneous nature of the name-bearing type series of this species requires the designation of a lectotype. Inger in Wallach et al. (2014: 624) designated specimen RMNH 1067 as the lectotype of this species. Unfortunately, this designation partly contravenes the requirements of Art. 74.7 of the Code (ICZN, 1999). Although Art. 74.7.1 is fulfilled, requirements of Art. 74.7.2 are limited to the collection number and total length of the specimen, and Art. 74.7.3, which requires an express statement of the taxonomic purpose of the designation, is neglected. Therefore, we consider the designation of this lectotype to not be valid.

In agreement with the Code, Art. 74.7, we here confirm the designation of the same specimen as the lectotype of Tropidonotus subminiatus with full compliance with Art. 74.7 of the Code, as follows: (1) in agreement with Art. 74.7.1, specimen RMNH 1067 is here designated as the lectotype of Tropidonotus subminiatus Schlegel, 1837; (2) in agreement with Art. 74.7.2, the lectotype, an adult male, is described in detail below; (3) in agreement with Art. 74.7.3, we designate this lectotype of $T$. subminiatus in order to eliminate any potential subsequent nomenclatural problem due to the heterogeneous original type series comprising four primary (same locality) and one secondary (erroneous locality) syntypes. This fixation precludes any ambiguity should the specimen depicted by Seba (1735) be rediscovered. In selecting specimen RMNH 1067, Inger in Wallach et al. (2014: 624) and our present confirmation of this selection unambiguously attach the taxon Tropidonotus subminiatus to the Javanese population.

The status of Tropidonotus manadensis Günther, 1873, described from Manado, northern Celebes (now North Sulawesi) remains controversial. We examined its holotype (NHMUK 1946.1.13.23, adult male, deposited by Dr. A.B. Meyer) and, by all our defined characters, it is a genuine Rhabdophis subminiatus. We have no doubt in including $T$. manadensis in the synonymy of $R$. subminiatus. De Rooij (1917) did not mention T. manadensis but she included T. subminiatus in the fauna of Celebes with the same locality than the holotype of this former taxon. De Lang \& Vogel (2005: 255 ) included $R$. subminiatus in their list of 
doubtful species in Sulawesi. However, Doria et al. (2013) listed a specimen of $R$. s. subminiatus, not seen by us, also from "Celebes". Obviously, the status of $R$. subminiatus in Sulawesi needs to be investigated.

Unfortunately, the holotype of Pseudoxenodon intermedius Lönnberg, 1899 is currently not traced. However, based on the original description, the type locality ("Buitenzorg, Java", now Bogor, West Java Province, Java, Indonesia) and the synonymies given by De Rooij (1917: 89) and Wallach et al. (2014: 624), we agree with the synonymy of this taxon with $R$. subminiatus.

Lastly, we here refer Natrix subminiata hongkongensis to the synonymy of $R$. subminiatus sensu stricto. Mell (1931: 203) described $N$. s. hongkongensis (type locality: "Hong Kong") without mentioning its namebearing types. Pope (1935: 132) considered this taxon to be a synonym of $N$. s. subminiata because this latter author pointed out the fact that Mell's taxon, $N$. s. hongkongensis was only based on specimens collected by J.C. Boring and cited by Boulenger (1893a: 256), and that these specimens [i.e. (1) adult male, NHMUK 1856.11.17.62; (2) adult female, NHMUK 1856.11.17.63; and (3) a juvenile (not located by us)], alleged to originate from Hong Kong, in fact most likely came from Java. Scalation data provided by Mell (1931) confirm this interpretation. Nevertheless, Rendahl (1937) recognized $N$. s. hongkongensis as a valid taxon.

As stated above, the former subspecies $R$. $s$. helleri deserves a full species status. Therefore, $R$. subminiatus is now monotypic.

Iconography in the literature. Rhabdophis subminiatus, as defined here, has been poorly depicted in the literature. Pictures and drawings showing this species are available (nonexhaustive list; in chronological order) in Jan \& Sordelli (1868: Pl. I: figure 3), Bourret (1936: 97: figure 39; after Jan \& Sordelli 1868; specimen from Java correctly referred to as Rhabdophis subminiatus), Tweedie (1954: 69: figure 16b; although $R$. subminiatus does not occur in West Malaysia, the drawing indeed depicts a specimen with its typical comma-like subocular streak), van Hoesel (1959: 127: figure 33 \& 34), Maradjo (1976: 20-21; as "Chrysopelea paradisi"), Campden-Main (1970: 52; drawing based on Tweedie "1953", most likely an Indonesian specimen), Tweedie (1983: 90: figure b), Suhono (1986: unnumbered figure), Kurniati (2003: 119: figure 91), Iskandar
\& Erdelen (2006: 082: Pl. 76), Marlon (2014: 171-172), Rusli (2016: 1, 99-100), de Lang (2017: 207-210: figure 153-156), and Kamsi et al. (2017: 232).

Lectotype (designated here). Adult male, RMNH.RENA 1067, collected from "à Java dans les champs de sawa inondés" (flooded paddy fields in Java, Indonesia), by $\mathrm{H}$. Boie \& H. Macklot, deposited by C.G.C. Reinwardt in between 1816 and 1821 .

Diagnosis. A medium-sized species of the genus Rhabdophis characterized by the combination of (1) 19 (rarely 17 or 21) - $19-17$ dorsal scale rows; (2) dorsal scales narrowly but strongly keeled, scales of $1^{\text {st }}$ DSR smooth; (3) nuchal groove not visible (exceptionally a shallow groove barely visible); (4) no enlarged (exceptionally slightly enlarged) nuchal scales; (5) VEN: 132-145; SC: 59-78, paired, (6) dorsum in various shades of olive-brown, greyish-brown or pale brown, distinctly chequered and spotted with dark grey or black, diffuse blotches; (7) a pale, i.e., cream or pale yellowish-brown, dorsolateral stripe most usually present on $5^{\text {th }}-6^{\text {th }}$ dorsal scale rows, either complete or reduced to a series of longitudinally aligned pale rectangular blotches; (8) nape very dark grey or black in juvenile specimens, dark green or brown in adults; (9) upper surface and sides of the neck and anterior part of the body extensively tinged with bright vermilion-red or coral; (10) a dark brown or black subocular streak usually present (exceptionally totally absent); (11) subocular streak shaped as a narrow vertical bar or as narrow streak curved downwards or even forwards (Fig. 2A-F), resembling a comma on left side of the head), rarely a broad vertical bar or as a thick streak initially directed backwards then curved downwards; (12) venter always pale, i.e., cream or creamish-yellow, with a dark dot on the tips of each ventral, rarely only on the anterior part of the venter. The comparisons between Rhabdophis subminiatus and the three other species treated here are given in the respective accounts of these species.

Description of lectotype. The main characters are as follows: SVL $402 \mathrm{~mm}$, TaL $145 \mathrm{~mm}$, TL $547 \mathrm{~mm}$; ratio Tal/TL 0.265 .

Body moderately stout, cylindrical; no nuchal groove visible; no distinctly enlarged and aligned scales behind the head; head distinct from the neck; snout elongate, obtuse as seen 


\section{Plate 18}
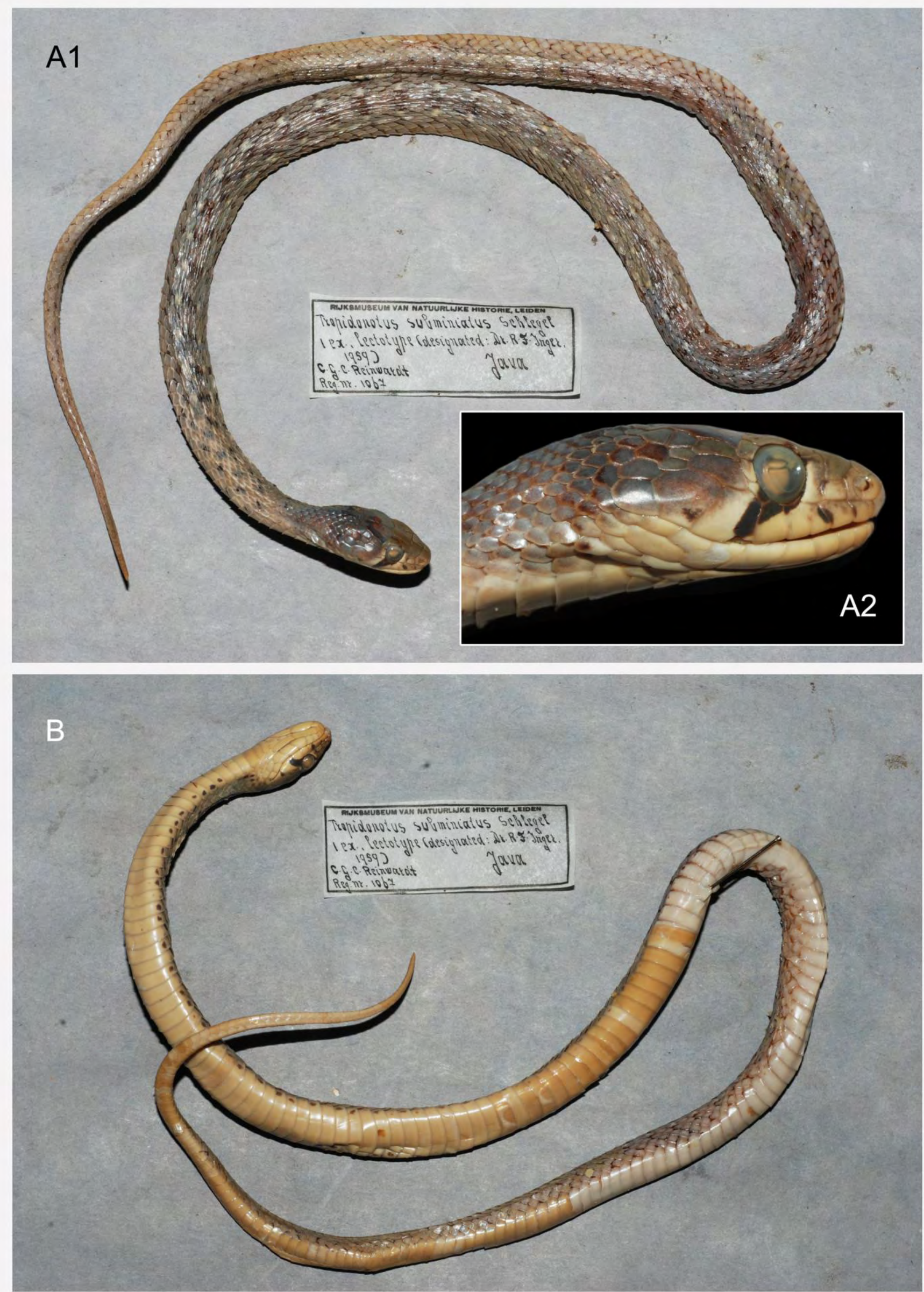

Figure 1. Rhabdophis subminiatus lectotype (RMNH 1067): (A1) full body dorsal view, (A2) head lateral view, and (B) full body ventral view. 


\section{Plate 19}
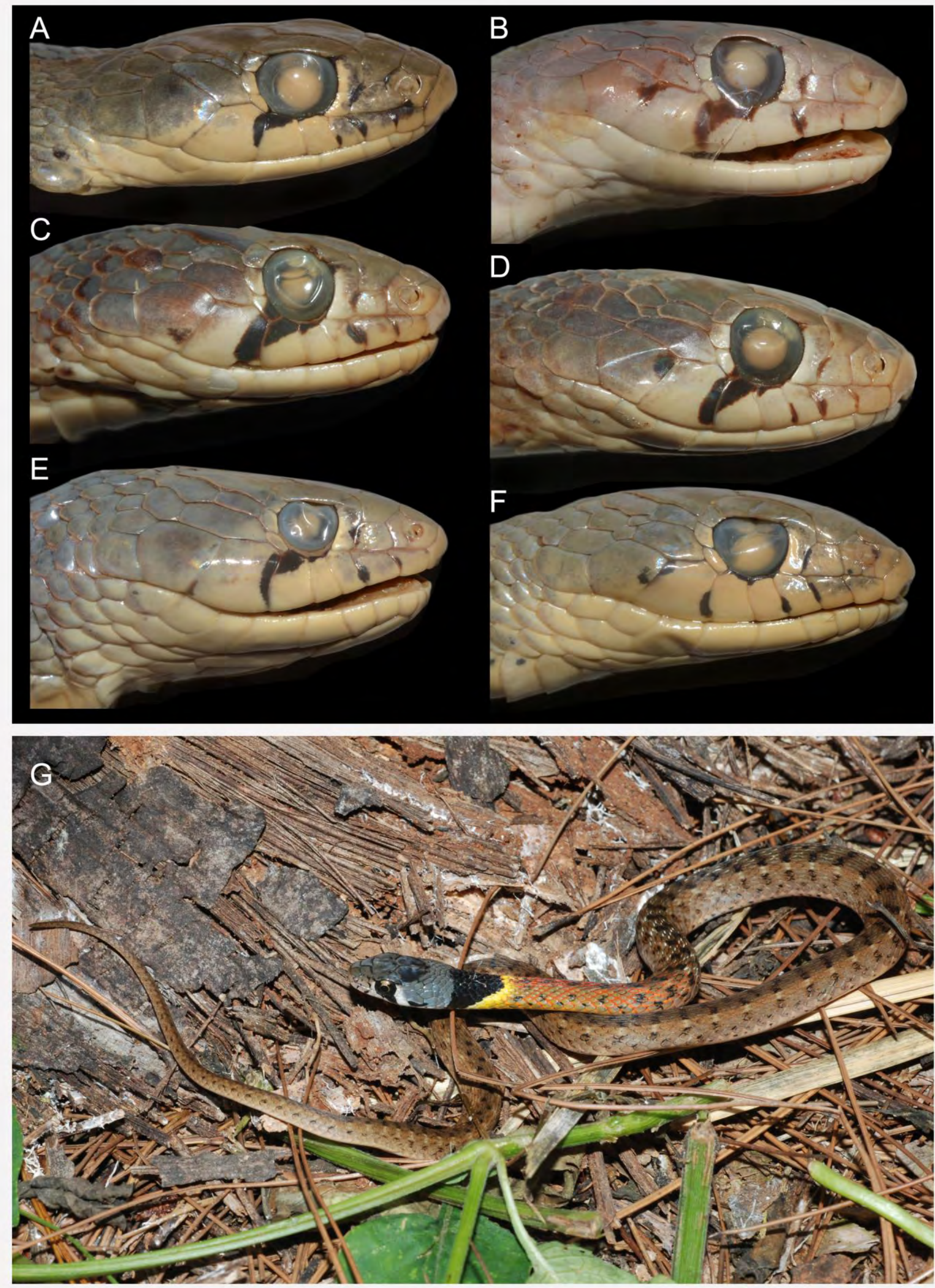

Figure 2. Lateral head colour pattern variation of adult Rhabdophis subminiatus from Java (A) NMW 22458:3, male; (B) ZMB 28363, male; (C) RMNH 1067 (lectotype), male; (D) RMNH 1066, (paralectotype), male; (E) ZMB 51785, female; (F) ZMB 51797, male; and (G) a live subadult (not collected), near Bogor, Java, Indonesia. 
from above, oblique seen in profile, about 1.6 times longer than diameter of eye; nostril lateral, small, crescent-shaped, piercing in the middle of the nasal; eye large, 1.9 times greater than the distance between its lower margin and the margin of the lip.

DSR $21-19-17$, strongly keeled, scales of the $1^{\text {st }}$ DSR smooth. VEN 140 (+2 preventrals); SC 73; cloacal plate divided.

Rostral barely visible from above; nasals pentagonal, elongate, much longer than high, vertically divided above and below the nostril; 1/1 loreal, pentagonal, elongate; 1/1 large preoculars; $3 / 3$ small postoculars; $8 / 8 \mathrm{SL}, 1^{\text {st }} / 1^{\text {st }}$ $\mathrm{SL}$ in contact with the nasal, $1^{\text {st }}-2^{\text {nd }} / 1^{\text {st }}-2^{\text {nd }} \mathrm{SL}$ in contact with the loreal, $3^{\text {rd }}-5^{\text {th }} / 3^{\text {rd }}-5^{\text {th }}$ touching orbit, $6^{\text {th }}$ and $7^{\text {th }}$ SL largest on both sides; $2 / 2$ anterior temporals, elongate, upper one smaller and shorter, followed by $3+3 / 3+3$ posterior temporals; $10 / 10 \mathrm{IL}$, first pair in contact, $1^{\text {st }}-5^{\text {th }}$ IL in contact with anterior chin shields; posterior chin shields longer than anterior ones.

Coloration of lectotype. In preservative, the dorsal surface and sides are dark greyish-brow, with scales indistinctly edged with cream on the anterior third of the body; irregular, more or less diffuse cream blotches on the sides and back throughout the body, more visible on its anterior half; two dorsolateral series of irregular, alternate dark brown blotches, well-distinct on the anterior quarter of the body and producing a chequered pattern, progressively vanishing and becoming poorly distinct posterior to midbody; a series of dark lateral blotches also visible only on the anterior part of the body; a series of pale, cream longitudinally aligned rectangular blotches on $5^{\text {th }}-6^{\text {th }}$ dorsal scale rows; occiput and nape very dark grey, ending in a triangularshaped collar of which the apex is on the vertebral row and the sides touch $2^{\text {nd }}-3^{\text {rd }}$ ventrals; a large area on the neck, behind the dark nape, mottled with reddish-brown, corresponding to the typical bright vermilion-red area in life. The tail is grey with irregular dark brown spots anteriorly, nearly uniform posteriorly.

The upper head surface is dark greenishgrey, much darker than the body and nearly as dark as the nape; rostral, sides of the snout and $1^{\text {st }}-2^{\text {nd }}$ supralabials pale brownish-yellow, paler than the upper head surface; preocular, $3^{\text {rd }}$ to $5^{\text {th }}$ supralabials and postoculars distinctly paler, i.e., pale yellowish-cream; $7^{\text {th }}$ and $8^{\text {th }}$ supralabials dark, coloured as the upper head surface; a short, vertically elongate, dark brown streak visible at left and right on the suture between the $2^{\text {nd }}$ and $3^{\text {rd }}$ supralabials; suture between the loreal and preocular dark brown on both sides; a conspicuous, blackish-brown, subocular streak on the posterior margin of $4^{\text {th }} \mathrm{SL}$ and anterior part of $5^{\text {th }} \mathrm{SL}$, rather narrow, shaped as a comma, namely initially directed backwards then distinctly curved downwards. Infralabials, chin and throat uniform yellowish-cream.

The venter is uniform yellowish-cream, with a dark dot on the tip of nearly each ventral plte of its anterior third; venter uniform backwards. Lower surface of tail uniform yellowish-cream with the tip of many subcaudals edged with dark greyish-brown.

Description of species. Body rather robust, stouter in large females, cylindrical; no visible nuchal groove (exceptionally a shallow groove barely visible); head elongate, rather thick, distinct from the neck; snout elongate, slightly depressed, obtuse as seen from above, oblique seen in profile, 1.6-1.8 times longer than diameter of eye; nostrils lateral and directed laterally, small, crescentic, piercing in the middle of the nasal; eye rather large, about 1.51.8 times greater than the distance between its lower margin and the margin of the lip, with a round pupil; tail long, rather thick at its base, cylindrical and tapering.

The maximal total length in our sample is $759 \mathrm{~mm}$ (SVL $585 \mathrm{~mm}$; TaL $174 \mathrm{~mm}$; specimen ZMB 51785, female). The longest known male in our sample is $563 \mathrm{~mm}$ long (SVL $410 \mathrm{~mm}$, TaL $153 \mathrm{~mm}$; ZMB 83095). This species reaches a moderate size. In our sample of 46 specimens, only three have a total length of at least $600 \mathrm{~mm}$.

Ratio TaL/TL: 0.215-0.273, with a weak sexual dimorphism.

24-27 maxillary teeth on each jaw, gradually enlarging, the last two abruptly and very strongly enlarged, without diastema.

DSR: (17)19(21) - 19 - 17 rows; scales strongly keeled with a narrow keel throughout the body; scales of $1^{\text {st }}$ DSR smooth. In our sample of 46 specimens, three have only 17 scale rows around the neck whereas three others have 21 scale rows.

Position of the dorsal scale rows reduction from 19 to 17 DSR: VEN 65-75 $(x=71.3, s d=$ 2.7).

Number of aligned, paired enlarged scales on the nape: 0 ( 2 in only one specimen with a shallow, barely visible nuchal groove). 
VEN: 132-145 (plus 1 or, usually, 2 preventrals); SC: 59-78, paired, without sexual dimorphism; cloacal plate divided. Ratio VEN/SC 1.81-2.39 $(x=2.00, s d=0.15)$.

Complement of upper head scales complete including 2 internasals, 2 prefrontals, 2 supraoculars, 1 frontal, and 2 parietals. Rostral wider than high, barely visible from above; nasals pentagonal, elongate, vertically divided above and below the nostril; internasals subtriangular, in broad contact with each other, longer than wide, moderately narrowing anteriorly and abruptly truncated; 2 prefrontals, distinctly broader than long, 1.1-1.2 times longer than internasals; frontal large, shield-like, longer than wide and 1.9-2.2 times longer than prefrontals; 1 supraocular on each side, subtriangular, 2.0-2.2 times longer than wide, narrower than internasals, about half as wide as frontal; parietals large and broad, 1.4-1.5 times longer than the frontal or suture between parietals 1.0-1.2 times longer than frontal; $1 / 1$ loreal, pentagonal, barely longer than high, in broad contact with the nasal; $1 / 1$ preocular in all examined specimens; $3 / 3$ elongate postoculars in all examined specimens; usually 8/8 SL (7/7 in 1 specimen, $7 / 8$ SL in two specimens, $8 / 9$ in four and 9/9 in one of the 46 examined specimens), the first five as long as high or longer than high, $1^{\text {st }}$ and $2^{\text {nd }} \mathrm{SL}$ in contact with the nasal, $2^{\text {nd }}$ or $2^{\text {nd }}-3^{\text {rd }} S L$ in contact with the loreal, usually $3^{\text {rd }}-$ $5^{\text {th }}$ SL touching the orbit (rarely $3^{\text {rd }}-4^{\text {th }}, 4^{\text {th }}-5^{\text {th }}$ or $\left.4^{\text {th }}-6^{\text {th }} \mathrm{SL}\right), 6^{\text {th }}$ and $7^{\text {th }}$ SL distinctly the largest; 2 (very rarely only 1 , in only 2 specimens) anterior temporals, much elongate, narrowing anteriorly, lower one largest, followed by 2 or 3 (rarely 1 or 4) posterior temporals, the most common total formula being $2+2$ or $2+3$ temporals; 9 or 10 (11 in only $2 / 92$ occurrences) infralabials, first pair in contact with each other behind the mental scale, $1^{\text {st }}-4^{\text {th }}$ or, most usually, $1^{\text {st }}-5^{\text {th }}$ IL in contact with anterior chin shields, $5^{\text {th }}, 6^{\text {th }}$ and $7^{\text {th }}$ IL largest; posterior chin shields narrower and longer than anterior ones.

Coloration of species. In preservative, the dorsal surface is pale brownish-grey, olivebrown or greyish-brown (the same in preservative and life), often distinctly darker on the $6^{\text {th }}$ or $7^{\text {th }}$ to $9^{\text {th }}$ upper dorsal scale rows and the vertebral row than on the lower sides; many dorsal scales are speckled with blackish-brown or black and, also, irregularly edged with cream on their lower and upper margins, producing an irregularly vermiculate pattern; often, a series of rectangular, blackish-brown or very dark grey blotches, 2 DSR wide, on scale rows bordering each side of the vertebral scale row; in many specimens, sides are ornate with one or two series of similar dark brown or dark grey, diffuse, rectangular blotches; most usually, a pale dorsolateral stripe, cream or pale yellowishbrown, extends on $5^{\text {th }}-6^{\text {th }}$ DSR from behind the neck up to the base of the tail, either complete or reduced to a series of longitudinally aligned, pale rectangular blotches; a dark brown or black chevron may be more or less visible just behind the head. Region of the nape uniform dark green, dark yellowish-ochre or brown above and on its sides downwards up to the ventrals; behind the nape, the upper part and sides of the body are yellowish-grey or yellowish-brown (conspicuously coloured in pale red, bright vermilion-red or coral in life) along a length equal to about 1.5 to 2.0 times the length of the head or 10 to 20 ventral scales before progressively vanishing; this pattern is due to the interstitial dorsal skin and edges of dorsal scales, or even a large part of the dorsal scales themselves, conspicuously tinged with red. The tail is as the dorsal surface in colour, with many scales finely edged with dark brown or black.

The head is dark olive-green, olive-brown or dark greyish-brown (the same in life); rostral, sides of the snout and $1^{\text {st }}$ and $2^{\text {nd }}$ supralabials distinctly paler than the crown, i.e., creamishgreen, pale yellowish-green or pale greenishbrown; preocular, $3^{\text {rd }}$ to $5^{\text {th }}$ or $6^{\text {th }}$ supralabials and postoculars pale yellowish-cream or pale creamish-green; $7^{\text {th }}$ and $8^{\text {th }}$ supralabials dark, coloured as the upper head surface; $3^{\text {rd }}-5^{\text {th }}$ supralabials narrowly edged with black on their anterior edge; on the limit between the $4^{\text {th }}$ and $5^{\text {th }}$ or $5^{\text {th }}$ and $6^{\text {th }}$ SL, a blackish-brown or black subocular streak is usually present, rarely totally absent (in about 10\% of the specimens examined or depicted in the literature); in most specimens in which it is present, this streak is shaped either as a narrow vertical bar or as a narrow streak strongly curved downwards or even forwards (looking as a comma on the left side of the head, as an inverted comma at right), rarely shaped as a broad vertical bar or as a thick streak initially shortly directed backwards then distinctly curved downwards (this subocular streak is only exceptionally shaped as a triangle directed backwards); often, a short, black spot along the limit between the $6^{\text {th }}$ and $7^{\text {th }}$ SL. Infralabials, chin and throat are uniform cream or yellowishcream.

The venter is uniform cream or yellowish- 
cream at the exception of a black dot on the tips of each or nearly each ventral, or, rarely only on ventrals of the anterior third of the body, uniform backwards. Under surface of tail dark uniform cream or yellowish-cream, outer edges of divided subcaudals narrowly edged with dark brown.

Juvenile specimens are coloured as adult but their pattern is much more contrasted. Dark dorsal blotches are conspicuous and often deep black; the nape is deep black, bordered with a bright yellow area behind, followed by the bright red area on the upper surface of the neck and anterior part of the body.

Sexual dimorphism. Beside the base of the tail distinctly bulging in adult males, a weak sexual dimorphism is expressed in the relative length of the tail: males $0.238-0.273(x=0.257$, $s d=0.011)$; females: 0.215-0.257 $(x=0.240$, $s d=0.053)$. We could not find any sexual dimorphism in the number of ventrals and subcaudals or in the colour pattern.

Distribution. (Fig. 9) Indonesia: Java: throughout the island. Sumatra: Aceh, North Sumatra, West Sumatra, Bengkulu, and South Sumatra; probably throughout the island (David $\&$ Vogel 1996). Nias Island. No specified locality. Sulawesi: North (?).

As defined here, $R$. subminiatus is endemic to Indonesia but it is not present on all major islands. De Rooij (1917), followed by Stuebing (1991), Das (2006, 2010) and Marlon (2014), included Kalimantan, the Indonesian part of Borneo Island, in the range of this species. However, we could not locate any voucher specimen from this island and, according to I. Das (pers. comm. on July 2019), this species most likely does not occur on Borneo. Furthermore, neither Stuebing \& Inger (1999) nor Stuebing et al. (2014) included it in the snake fauna of this island.

Sworder (1924) added Natrix subminiata to the snake fauna of Singapore based on a communication from M. Smith: "Dr. Malcolm Smith tells me that he obtained two specimens when he was in Singapore". It is unclear whether these specimens were caught or purchased on a market by M. Smith. Nevertheless, Smith (1930) mentioned again Natrix subminiata from Singapore, followed by $\operatorname{Lim} \& \operatorname{Lim}(1992,2002)$ who merely cited this species in checklists but without any evidence to support its occurrence in Singapore. More recently, Teo \& Rajathurai (1997) also recorded a specimen from Singapore. According to these authors, a single specimen of this species was recorded in 1994 but these authors suggested that this animal escaped from the Singapore Zoological Gardens. According to K. K. P. Lim (pers. comm., July 2019), there is no authenticated natural record of $R$. subminiatus from Singapore. Therefore, we do not include this species in the fauna of this country. Lastly, the record from Ternate Island, cited by Boulenger (1893a), is highly doubtful and, most likely, results from an error of locality.

Rhabdophis siamensis (Mell, 1931) comb. nov. (Figs. 3, 4, 9; Table 3)

Natrix subminiata siamensis Mell, 1931: 203

Natrix (Rhabdophis) laobaoensis Bourret, 1934: 169 (p. 5 of the separate)

Taxonomic history. Mell (1931: 203) described Natrix subminiata siamensis based on an unspecified number of syntypes from "Siam" and "Hainan", none of which was identified by a collection number in the original description. Nevertheless, the catalogue of the collections of the "Zoologisches Museum für Naturkunde der Humboldt-Universität zu Berlin" identifies two of them, ZMB 29237 from "Hainan", now Hainan Island, China (adult female; deposited by Mr. Schoede), and ZMB 30222 from "Siam" i.e. Thailand (adult female; deposited by $\mathrm{Mr}$. Budenbender). In agreement with Art. 74.7.1 of the Code (ICZN 1999), we here select specimen ZMB 30222, from "Siam", as the lectotype of $N$. s. siamensis. In agreement with Art. 74.7.2, we describe in detail this lectotype below. Lastly, in agreement with Art. 74.7.3, we select a lectotype in order to fix the status of the taxon siamensis as the correct name of the species widespread in Indochina, Thailand, southern Myanmar, and northern West Malaysia. The designation of the lectotype from "Siam" makes this specimen the unambiguous name-bearing type of the Asian mainland populations. The other syntype(s) of N. s. siamensis originated from Hainan Island, a province of the People's Republic of China. We discuss below the status of the specimens from this island, which belong to a distinct undescribed taxon.

Natrix (Rhabdophis) laobaoensis Bourret, 1934 was described based on a single specimen, MNHN 0121, originating from "Lao Bao (Chaîne Annamitique altitude $300 \mathrm{~m}$ )", now Lao Bao, Truong Son Range, Quang Tri Province, Vietnam. Bourret compared his new taxon only 
with Rhabdophis speciosus Wall, 1925, currently a junior synonym of Rhabdophis himalayanus (Günther, 1864). We examined the holotype and it agrees in all points with the diagnosis of Rhabdophis siamensis.

Based on its scalation and pattern, Pope (1935: 132) considered N. s. siamensis to be a synonym of $N$. s. subminiata. This combination was nevertheless considered valid by Rendahl (1937). Subsequently, following Smith (1943), all subsequent authors accepted the synonymy of $N$. s. siamensis with $N$. s. subminiata or $R$. $s$. subminiatus. In contrast, Deuve (1961a: 376, 1961b: 14) recognized the 'subvariety' Rhabdophis subminiatus subminiatus siamensis. This odd combination was again used by Deuve (1970: 105: Pl. IX, 106 \& 108). Other authors did not discuss the validity of the taxon siamensis that has constantly been considered a synonym since Smith (1943).

We here resurrect this taxon, at full species status as Rhabdophis siamensis, from the synonymy of $R$. s. subminiatus sensu Pope (1935) and Smith (1943). As currently conceived, Rhabdophis siamensis comb. nov. is a monotypic species.

Iconography in the literature. Rhabdophis siamensis, as defined here, has been widely depicted in the literature under the combination Rhabdophis subminiatus or $R$. subminiatus subminiatus. Indeed, most papers, books and field guides about snakes of South-east Asia, i.e., out of China and India, depicting $R$. "subminiatus" show specimens of $R$. siamensis. Pictures and drawings showing this species are available in the following publications (nonexhaustive, subjective list, in chronological order): Bourret (1936: 90: figure 36; as Rhabdophis laobaoensis); Taylor (1965: 853: figure 60), Deuve (1970: 105: Pl. IX: figures 14), Saint Girons (1972: Pl. XX: figure 1), Lim \& Lee (1989: 60), Cox (1991: 269: Pl. 79-80), Manthey \& Grossmann (1997: 389: figure 297), Cox et al. (1998: 47), Bulian (1999: 64), Chanard et al. (1999: 186-188), Ziegler (2002: 258260, figures 387-390), Shah \& Tiwari (2004: 188; although this reference deals with reptiles of Nepal, the depicted specimen is a typical $R$. siamensis from Phang-Nga Province, Thailand, as specified by Frank Tillack, pers. comm., March 2020), Nguyen et al. (2009: 635: figure 491), Teynié \& David (2010: 232-233), Cox et al. (2012: 426), Jestrzemski et al. [2013: 99: figure 15 (4)], Nemes et al. (2013: 321: figure 31), Sharma et al. (2013: 65; specimen from
Phang-Nga Province, Thailand, as specified by Frank Tillack, pers. comm., March 2020); Chanard et al. (2015: 227, 228: figure 267), Currin (2016: 119: figure 14), Vassilieva et al. (2016: 260: figure 317, 261: figures 318-320), and Charlton (2019: 214-215).

Lectotype (designated here). Adult female, ZMB 30222, collected from "Siam" (Thailand), deposited by Mr. Budenbender; no date of collect given.

Diagnosis. A moderately-sized species of the genus Rhabdophis characterized by the combination of (1) 19(rarely 17,18 or 21) - 19 17(rarely 16 or 18) dorsal scale rows; (2) dorsal scales narrowly but strongly keeled, scales of $1^{\text {st }}$ DSR smooth; (3) nuchal groove always present, moderate to strong; (4) 3-8 enlarged, paired nuchal scales; (5) VEN 137-156, SC 65-89, paired; (6) dorsum yellowish-grey, greyishbrown or pale brown, distinctly spotted with black and cream blotches; (7) upper surface and sides of the neck bright vermilion-red, sometimes subdued in larger specimens or in long-preserved specimens; (8) a dark brown or black subocular streak always present; (9) dark subocular streak shaped as a broad triangular streak (rarely faint), directed backwards; (10) venter pale, i.e., cream or creamish-yellow, without dark dots on the tips of ventrals, or only on the anterior part of the venter.

Rhabdophis siamensis comb. nov. differs from Rhabdophis subminiatus by the following characters:

(1) the number of ventral plates (weak sexual dimorphism, sexes combined), 137-156 $(x=146.0 ; s d=5.4)$ in $R$. siamensis vs. $132-145$ ( $x=136.8 ; s d=2.6)$ in $R$. subminiatus. These values suggest a large overlap in the numbers of ventrals but a Mann-Whitney $U$-test (one-tailed) gives a level of difference between the samples significant at $p<0.001(U=455.5$; z-score $=$ 6.67568). If the difference is tested on the number of ventral plates in males only, the values are 134-143 in $R$. subminiatus vs. 137156 in $R$. siamensis. These values also suggest a large overlap in the numbers of ventral plates but a Mann-Whitney $U$-test (one-tailed) gives a level of difference between the samples significant at $p<0.001(U=93.0$; z-score $=$ 4.96524). Result in taking into account females only is similar and is not detailed here.

(2) the number of subcaudals in males, 72 $89(x=79,9 ; s d=5.4)$ in $R$. siamensis vs. $65-78$ in $R$. subminiatus. A Mann-Whitney $U$-test (one- 


\section{Plate 20}
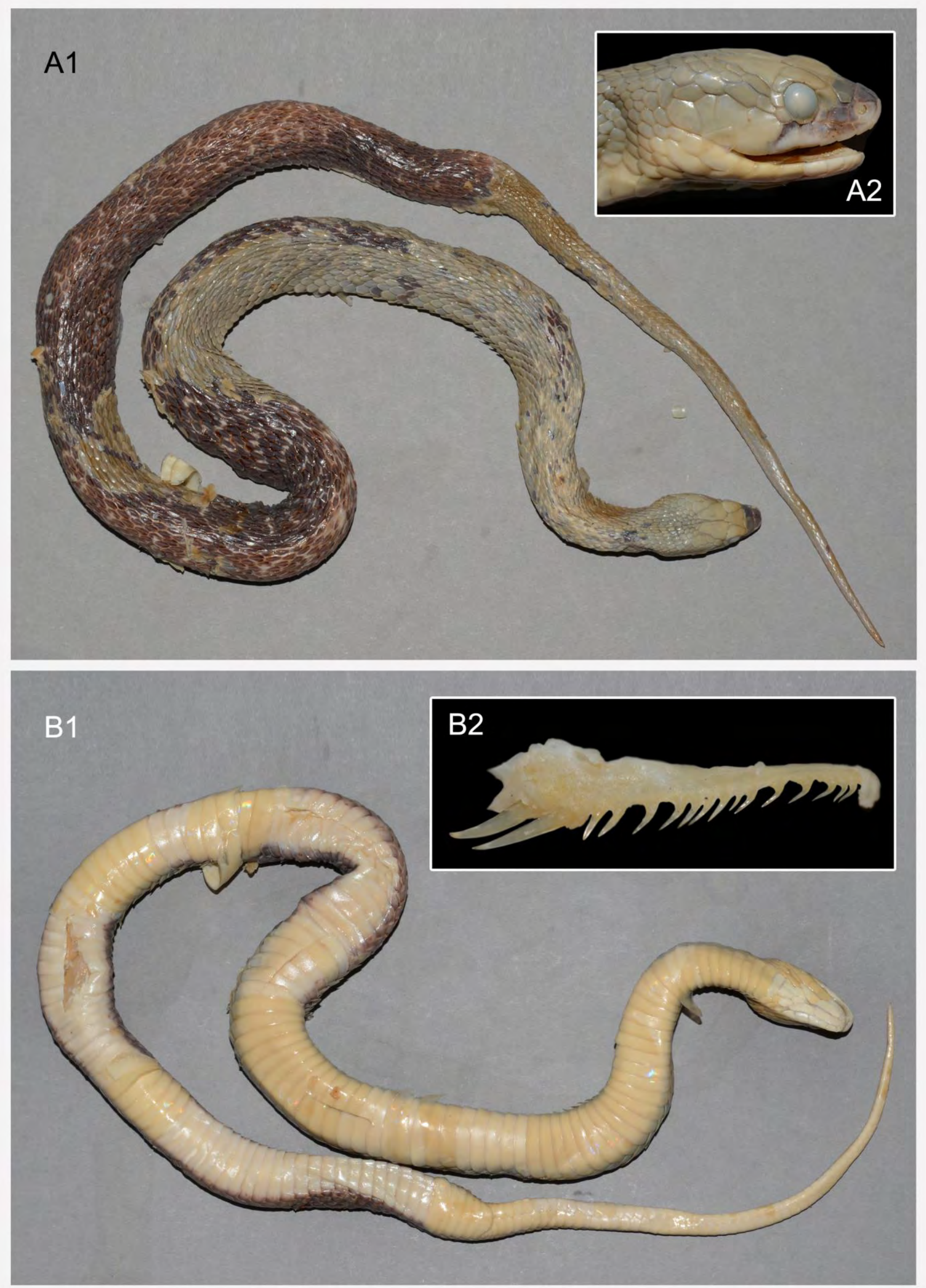

Figure 3. Rhabdophis siamensis lectotype (ZMB 30222): (A1) full body dorsal view, (A2) head lateral view, (B1) full body ventral view, and (B2) maxilla (FMNH 259207) 


\section{Plate 21}
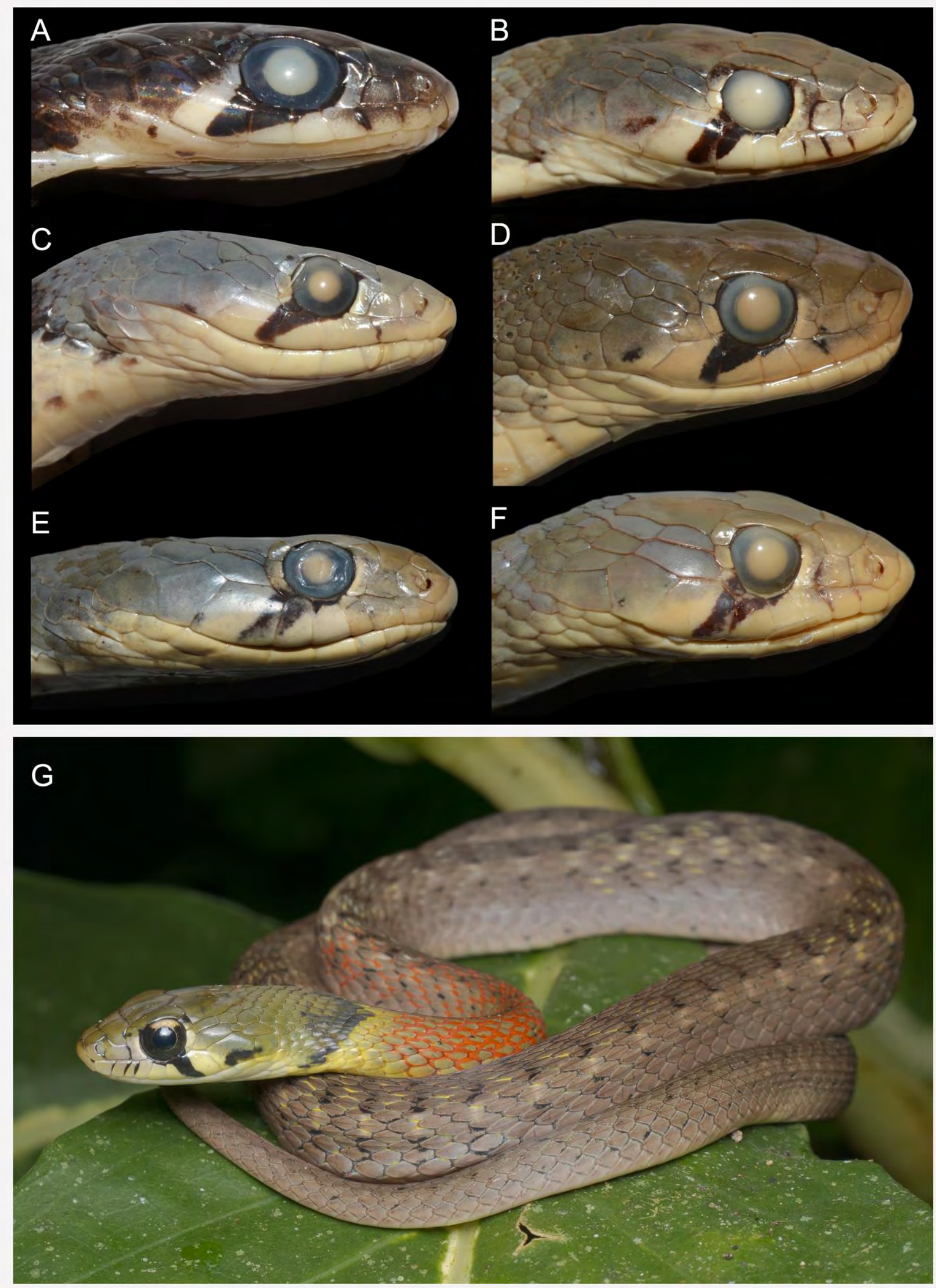

Figure 4. Lateral head colour pattern variation of adult Rhabdophis siamensis (A) FMNH 259209, male; (B) ZMB 57405, female; (C) NMW 22464:2, female; (D) NMW 22465:2, male; (E) NHMUK 1969.1755, female; (F) BMNH 84.5.8.10, male; and (G) a live adult (not collected) from Khao Sok, Thailand; (C) Photo: P. Pawangkhanant. 
tailed) gives a level of difference between the samples significant at $p<0.001(U=38.0$; zscore $=4.45761$ ).

(3) the nuchal groove is always present, moderate to strong in $R$. siamensis vs. invisible (weakly visible in one specimen);

(4) 3-8 enlarged, aligned paired nuchal scales vs. 0 aligned and enlarged scale ( 2 aligned pairs in only one specimen);

(5) shape of the dark subocular streak: streak shaped as a conspicuous (rarely faint or incomplete), broad, triangle (looking like a shark fin), its apex directed both downwards and distinctly backwards in $R$. siamensis vs. a streak shaped as a narrow, vertical bar, its apex directed downwards, or as a curved streak directed downwards or downwards and forwards when the streak looks like a comma, or also shaped as a broad streak initially directed backwards then curved downwards in $R$. subminiatus (never a triangle directed backwards);

(6) venter cream or yellowish-cream without a dark dot on the tip of each ventral plate, or present only on the anterior part of the venter, vs. venter with a dark dot on the tip of each ventral (rarely only on the anterior part of the venter);

The general dorsal pattern is quite similar in these two species, although the background colour is paler and the dorsal pattern more contrasted in $R$. subminiatus than in $R$. siamensis. The pale dorsolateral stripe or series of aligned blotches edging the darker upper dorsal scale rows, most usually present in $R$. subminiatus, are absent in $R$. siamensis. Lastly, the red area of the neck is somewhat longer in $R$. siamensis.

Rhabdophis siamensis comb. nov. differs from Rhabdophis helleri by the following main characters:

(1) the difference in total size, about $80 \mathrm{~cm}$ in R. siamensis vs. up to $130 \mathrm{~cm}$ in R. helleri;

(2) the number of ventrals: $137-156(x=$ $146.3, s d=5.1)$ in $R$. siamensis vs. $157-178(x=$ $165.3, s d=3.6)$ in $R$. helleri;

(3) the number of subcaudals (both sexes altogether): $65-89(x=77.5, s d=6.0)$ in $R$. siamensis vs. 75-97 $(x=84.5, s d=3.4)$. These values suggest a large overlap in the numbers of subcaudals but a Mann-Whitney $U$-test (onetailed) gives a level of difference between the samples significant at $p<0.001(U=368.5$; zscore $=-4.46731)$;

(4) the position of the dorsal scale rows reduction, expressed in number of ventral plates: 75-85 ( $x=80.0, s d=2.6)$ in $R$. siamensis vs. 82-93 $(x=87.4, s d=2.5)$;

(5) nuchal groove usually moderate or even poorly visible, rarely strong in $R$. siamensis vs. strong and well-visible.

(6) dark subocular streak always present and shaped as a broad, triangle (rarely faint), directed backwards in $R$. siamensis vs. either totally absent or reduced to a few dots, or incomplete, or, more rarely, well-defined as a vertical bar, an incomplete triangle directed backwards, more or less faint and looking like being "washed out" in its centre, or as a broad comma, rarely solid black and well-visible.

(7) dorsum yellowish-grey, greyish-brown or pale brown, distinctly spotted with black and cream blotches in $R$. siamensis vs. dorsum rather dark, dark olive green or dark grey, nearly uniform or chequered with black anteriorly.

(8) venter entirely cream or creamishyellow, without dark dots on the tips of ventrals, or only on the anterior part of the venter in $R$. siamensis vs. venter cream or pale creamishyellow on a short distance behind the head becoming heavily dotted or speckled with dark grey posteriorly.

The differences between $R$. siamensis and the new species described here are given under the diagnosis of this latter species.

Description of lectotype. The main characters are as follows: SVL $540 \mathrm{~mm}, \mathrm{TaL}>153 \mathrm{~mm}$, incomplete, TL > $693 \mathrm{~mm}$.

Body moderately stout, cylindrical; a distinct nuchal groove, edged with 5 pairs of aligned, enlarged scales besides the head; head distinct from the neck; snout elongate, obtuse as seen from above, oblique seen in profile, 1.6 times longer than diameter of eye; nostrils lateral, small, crescentic, piercing in the middle of the nasal; eye large, 1.5 times greater than the distance between its lower margin and the margin of the lip.

DSR $21-19-17$, distinctly and strongly keeled, scales of the $1^{\text {st }}$ DSR smooth. VEN 141 (+ 2 preventrals); SC 66, all paired; cloacal plate divided.

Position of the dorsal scale rows reduction from 19 to 17 DSR: VEN 75/77.

Rostral barely visible from above; nasals pentagonal, elongate, much longer than high, vertically divided above and below the nostril; 1/1 loreal, pentagonal, elongate; 1/1 large preoculars; $3 / 3$ small postoculars; 9/8 $\mathrm{SL}, 1^{\text {st }}$ 
$2^{\text {nd }} / 1^{\text {st }}-2^{\text {nd }}$ SL in contact with the nasal, $2^{\text {nd }}$ $3^{\text {rd }} / 2^{\text {nd }}-3^{\text {rd }}$ SL in contact with the loreal, $3^{\text {rd }}-$ $5^{\text {th }} / 3^{\text {rd }}-5^{\text {th }}$ entering orbit, $6^{\text {th }}$ SL (at left; $7^{\text {th }}$ SL divided into two tall, narrow scales), $6^{\text {th }}$ and $7^{\text {th }}$ SL (at right) largest; 2/2 anterior temporals, elongate, upper one smaller and shorter, followed by $3 / 3$ posterior temporals; 11/10 IL, first pair in contact, $1^{\text {st }}-5^{\text {th }}$ IL in contact with anterior chin shields; posterior chin shields longer than anterior ones.

Coloration of lectotype. The dorsal surface and sides are yellowish-grey, with scales indistinctly edged or speckled with cream, more distinct on the anterior half of the body; some irregular dark grey spots; a large area behind the neck mottled with pinkish-yellow (probably the typical bright vermilion-red in life). The tail is uniform yellowish-grey.

The head is greenish-grey, darker than the body; rostral, sides of the snout and supralabials paler greenish-grey, paler than upper head surface; some dark brown dots visible at right on the suture between the $2^{\text {nd }}$ and $3^{\text {rd }}$ supralabials, not visible at left; a distinct, blackish-brown, subocular streak on $4^{\text {th }}$ and especially $5^{\text {th }} \mathrm{SL}$, more visible at left than at right (probably faint due to the storage in preservative), nevertheless distinctly triangular and directed backwards. Infralabials, chin and throat uniform yellowishcream, devoid of any marking.

The venter is uniform yellowish-cream, with only the tip and outer part of each ventral clouded with dark greyish-brown but without any distinct dark spot. Lower surface of tail uniform yellowish-cream with the tip and outer part of each subcaudal clouded with dark greyish-brown.

Description of species. Body rather robust, stouter in large females, cylindrical; nuchal groove always present, moderate to strong; head elongate, rather thick, distinct from the neck; snout elongate, slightly depressed, obtuse as seen from above, oblique seen in profile, 1.6-1.8 times longer than the diameter of eye; nostrils lateral and directed laterally, small, crescentic, piercing in the middle of the nasal; eye rather large, its diameter 1.6-1.8 times greater than the distance between its lower margin and the margin of the lip, with a round pupil; tail long, rather thick at its base, cylindrical and tapering.

The maximal total length in our sample is $772 \mathrm{~mm}$ (SVL $569 \mathrm{~mm}$; TaL $203 \mathrm{~mm}$; specimen MNHN-RA 1974.1290, female). The longest known male in our sample is $737 \mathrm{~mm}$ long (SVL
$528 \mathrm{~mm}$, TaL $209 \mathrm{~mm}$; ZMB 263010). This species may reach greater total lengths as we have examined a specimen with a SVL > 600 $\mathrm{mm}$. In our sample of 79 specimens, 18 have a total length over $600 \mathrm{~mm}$ and only 5 are over $700 \mathrm{~mm}$ long.

\section{Ratio TaL/TL: 0.238-0.303.}

22-25 maxillary teeth on each jaw, gradually enlarging, the last two abruptly and very strongly enlarged, without diastema.

DSR: $(17,18) 19(21)$ - 19 - (16)17(18) rows; scales strongly keeled with a narrow keel throughout the body; scales of $1^{\text {st }}$ DSR smooth. In our sample of 79 specimens, four have only 17 scale rows around the neck, three specimens have 18 scale rows whereas three others have 21 scale rows. Near vent, only one specimen has 16 DSR whereas only one has 18 rows.

Number of aligned, paired enlarged scales on the nape: 3-8 (usually 5-7).

VEN: 137-156 (plus, most usually, 2 preventrals, rarely 1); SC: 65-89, paired, without sexual dimorphism; cloacal plate divided. Ratio VEN/SC 1.62-2.14 $(x=1.89$, $s d=0.12$ ).

Position of the dorsal scale rows reduction from 19 to 17 DSR: VEN 75-85 $(x=80.0, s d=$ 2.6).

Arrangement of upper head scales complete including 2 internasals, 2 prefrontals, 2 supraoculars, 1 frontal, and 2 parietals. Rostral wider than high, visible from above; nasals pentagonal, elongate, much longer than high, vertically divided above and below the nostril, with the posterior part larger than anterior one; internasals subtriangular, in broad contact with each other, longer than wide, moderately narrowing anteriorly and abruptly truncated; 2 prefrontals, distinctly broader than long, 1.0-1.2 times longer than internasals; frontal large, shield-like, longer than wide and 2.0-2.3 times longer than prefrontal; 1 supraocular on each side, subtriangular, 2.0-2.2 times longer than wide, narrower than internasals; parietals large and broad, 1.4-1.5 times longer than the frontal or suture between parietals 1.0-1.2 times longer than frontal; $1 / 1$ loreal, subrectangular or pentagonal, barely longer than high, in broad contact with the nasal; $1 / 1$ preocular in all examined specimens but one, in which the preocular is divided into 2 scales; $3 / 3$ elongate postoculars (exceptionally 2 or 4 ); usually $8 / 8$ but also $8 / 9$ or $9 / 8$, or $9 / 9$ supralabials ( $8 / 9$ or $9 / 8$ in 14 specimens and 9/9 in only two specimens), the first five as long as high or longer than high, 
$1^{\text {st }}$ and $2^{\text {nd }} \mathrm{SL}$ in contact with the nasal, $2^{\text {nd }}$ or $2^{\text {nd }}-3^{\text {rd }}$ SL in contact with the loreal, usually $3^{\text {rd }}$ $5^{\text {th }}$ SL touching orbit, also $4^{\text {th }}-5^{\text {th }}$ (in 12 specimens) or $4^{\text {th }}-6^{\text {th }}$ (in 17 specimens); $6^{\text {th }}-7^{\text {th }}$ SL or $6^{\text {th }}-8^{\text {th }}$ SL (in specimens with 9 SL) distinctly the largest; 2 anterior temporals (1 in only 2 specimens), much elongate, narrowing anteriorly, lower one largest, followed by 2 or 3 (rarely 1) posterior temporals, the most common total formula being $2+2$ or $2+3$ temporals; usually 10 infralabials, rarely 8 (in 2 specimens), 9 (in five specimens) or 11 (in 11 specimens), first pair in contact, $1^{\text {st }}-4^{\text {th }}$ or, most usually, $1^{\text {st }}-$ $5^{\text {th }}$ IL in contact with anterior chin shields (rarely $\left.1^{\text {st }}-6^{\text {th }}\right), 5^{\text {th }}, 6^{\text {th }}$ and $7^{\text {th }}$ IL largest; posterior chin shields narrower and longer than anterior ones.

Coloration of species. In preservative, the dorsal surface is usually sea-grey or dark grey, olive-brown or dark brownish-grey (the same in life), somewhat darker on the upper dorsal scale rows in some specimens; many dorsal scales speckled with blackish-brown or black and also irregularly edged on their upper and lower margins with cream or pale yellow, producing an irregularly vermiculate pattern, more visible on the forepart of the body; a series of dark, blackish-brown or very dark grey, rectangular spots or blotches, one to two DSR wide, on the dorsal rows bordering each side of the vertebral scale row, or straddling over the vertebral row; 2 or 3 series of similar diffuse, rectangular, dark grey or black blotches on the upper and middle scale rows of the sides of the body; a dark brown or black chevron may be more or less visible just behind the occiput; region of the nape, above and on its sides downwards up to the ventrals, uniform dark green, olive green or yellowishochre, not darker than the background colour of the sides of the body; behind the nape, upper surface and sides of the neck yellowish-grey or yellowish-brown (conspicuously coloured in deep red or vermilion-red in life) along a length equal to about 1.5 to 2.0 times the length of the head or 15 to 25 ventral scales before progressively vanishing; this pattern is due to the interstitial dorsal skin and edges of dorsal scales, or even a large part of the dorsal scales themselves, conspicuously tinged with red. The tail is as the dorsal surface in colour, with many scales finely edged with dark brown or black.

The head is dark olive-green, dark greyishgreen or greyish-brown (the same in life); rostral, sides of the snout and $1^{\text {st }}$ and $2^{\text {nd }}$ supralabials distinctly paler than the upper head surface i.e., creamish-green, greenish-grey or pale greenish-brown; preocular, $3^{\text {rd }}$ to $5^{\text {th }}$ or $6^{\text {th }}$ supralabials and postoculars distinctly paler, i.e., pale yellowish-cream, creamish-green or pale yellowish-green; $7^{\text {th }}$ and $8^{\text {th }}$ supralabials dark, coloured entirely or in their upper part as the upper head surface; a conspicuous, black or dark grey subocular streak, shaped as a triangle directed downwards and backwards extends on the limit between the $5^{\text {th }}$ and $6^{\text {th }}$ SL, its apex reaching the edge of the lip, rarely totally absent (in only 1 specimen), usually solid, sometimes strongly faded in its middle. Infralabials, chin and throat are uniform cream or yellowishcream.

The venter is uniform cream or yellowishcream, usually without any black dot (in 67 examined specimens) or only on ventrals of the anterior third of the body (in 12 examined specimens), uniform backwards; outer edge of ventrals dark as the dorsal colour. Under surface of tail dark uniform cream or yellowish-cream, outer edges of subcaudals narrowly edged with dark grey.

Juvenile specimens are coloured as adult but their pattern is much more contrasted; dorsal dark blotches are deep black; the head is dark green or dark grey above; the nape is deep black, bordered with a more or less extensive area of bright yellow behind, followed by the bright red upper surface and sides of the neck.

Sexual dimorphism. As in $R$. subminiatus, the base of the tail is distinctly bulging in adult males. A weak sexual dimorphism is expressed in the relative length of the tail: males $0.249-$ $0.303(x=0.271, s d=0.016)$; females: $0.236-$ $0.280(x=0.257, s d=0.011)$. We could not find any sexual dimorphism in the number of ventrals and subcaudals or in the color pattern.

Distribution. (Fig. 9) People's Republic of China: extreme southern Yunnan Province only: Xishuangbanna Dai Autonomous Prefecture (based on Liu et al. 2021: 1375, figure 1); Laos: Centre and south: recorded from the provinces of Attapeu, Bokeo, Bolikhamxai, Champasak, Khammouan, Louangphabang, Savannakhet, Vientiane Xaignabouli, Xekong, and from Vientiane Prefecture. Vietnam: Centre and south, northern limit uncertain; definitely recorded from the provinces of Binh Phuoc, Dak Lak, Da Nang, Dong Nai, Gia Lai, Ha Tinh, Ho Chi Minh City, Kien Giang, Kon Tum, Lam Dong, Nghe An, Quang Binh, Quang Nam, Quang Ngai, Quang Tri, Tay Ninh, Thanh Hoa, and Thua Thien-Hue (Nguyen et al. 2009); 
Cambodia: widespread in the country; Thailand: Throughout the country except the extreme north; recorded from the provinces of Bangkok, Buriram, Chaiyaphum, Chanthaburi, Kalasin, Kanchanaburi, Khlong Kaeng, Krabi, Lamphun, Loei, Nakhon Nayok, Nakhon Ratchasima, Nakhon Si Thammarat, Nan, Narathiwat, Nong Khai, Nonthaburi, Pattani, Phang-Nga, Phattalung, Phetchabun, Phetchaburi, Prachinburi, Phuket, Ratchaburi, Ranong, Rayong, Sisaket, Surin, Surat Thani, Surin, Tak, Trang, Trat, Ubon Ratchathani, Udon Thani, Uthai Thani, and Yala (Nabhitabhata et al. 2004, Cox et al. 2012, Sjon Hauser, pers. comm. February 2020); Myanmar: South: regions of Ayeyarwady, Yangon and Tanintharyi (Liu et al. 2021; our material); Federation of Malaysia: Recorded only from the northern states of West Malaysia: states of Perak and Kedah, and, possibly the states of Penang and Terengganu (Tom Charlton, pers. comm., February 2020).

The northern limit of this species is uncertain in both Thailand and Vietnam. In this latter country, $R$. siamensis occurs as far north as the province of Thanh Hoa. In Thailand, Taylor \& Elbel (1958: 1153) reported seven specimens of $R$. subminiata helleri from Loei Province; however, we refer the seven specimens to $R$. siamensis, and not to $R$. helleri as defined below. Specimens from Phu Luang depicted in Chanard et al. (1999: 186-187) also possibly refer to $R$. siamensis. Thanks to the courtesy of Sjon Hauser (pers. comm., February 2020), we have obtained data and pictures of specimens from the Thai provinces of Lamphun (south: Li District), Nan and Tak; all are undoubtedly referable to $R$. siamensis. Therefore, the northern limit of the range of $R$. siamensis in Thailand probably lies across southern Nan and Lamphun provinces.

\section{Rhabdophis helleri (Schmidt, 1925)}

(Figs. 5, 6, 9; Table 3)

Natrix helleri Schmidt, 1925: 3

Taxonomic history. Schmidt (1927b: 515), in an expanded description of Natrix helleri, stated that this new species is "closely allied to $N$. subminiata of Java and South-eastern Asia, from which it is distinguished by a higher number of ventral scales, 160-172, compared with 132-157 in N. subminiata as here restricted." Quite correctly, Schmidt noticed the difference in the number of ventrals between the taxa $R$. helleri and $R$. subminiatus auctorum.
In contrast, Mell (1931: 203) regarded Natrix helleri Schmidt, 1925 to be a subspecies of Natrix subminiata. As stated above, all authors who have dealt with this taxon since Mell (1931), including Pope (1935), Smith (1943), Taylor \& Elbel (1958), Taylor (1965) and Romer (1979a), among others, considered $R$. helleri to be a subspecies of Natrix subminiata or Rhabdophis subminiatus. This arrangement is still widely used in the literature, for example, implicitly, by Wallach et al. (2014), Boundy (2020) and Wang et al. (2020).

Eventually, based in part on Takeuchi et al. (2018) and, mainly, on their own molecular phylogenies that we discuss below, Liu et al. (2021) rose $R$. s. helleri auctorum to full species status - see the Discussion. Our morphological data indeed pointed out several major morphological differences between $R$. helleri and $R$. siamensis that confirm the species level of $R$. helleri. Furthermore, Liu et al. (2021) identified two subclades referable to $R$. helleri in their phylogenetic tree. As we could not identify any morphological difference between specimens of these two subclades, we refrain to grant them a taxonomic status. Therefore, as defined here, $R$. helleri is monotypic.

Iconography in the literature. - Under the names Natrix subminiata helleri or Rhabdophis subminiatus helleri, $R$. helleri has been extensively depicted in the literature, even more than $R$. siamensis, especially in Chinese and Indian publications. Pictures and drawings showing this species are available (nonexhaustive list; in chronological order) in Schmidt (1927b: 515: figure 11), Pope (1935: 133: figure 30), Bourret (1936: 98: figure 40), Reitinger (1978: figure 17), Romer (1979b: p. 3), Hu et al. (1980: Pl. 47; 79: figure 83), Romer (1983: Pl. IX), Wu et al. (1985: 221: figure 74; 435: figure 36-2), Karsen et al. (1986: 87; 1998: 132), Zhao \& Adler (1993: Pl. 38H), Karsen et al. (1998: 132), Zhao et al. (1998: Col. Plate II: figure 5), Das (2002: 44), Schleich \& Kästle (2002: Pl. 99: figure 297; 918: figure 1; 919: figures 2-3; very unusual head pattern, see below), Zhao \& Huang (2003: 190), Whitaker \& Captain (2004: 233), Zhao (2006: Vol. II, p. 225: figure 153-1), Ahmed et al. (2009: 96), Kamruzzaman (2009: 147), Yang \& Rao (2008: 378: figures 40-41), Zhang (2009: figure 140), Nguyen et al. (2009: 635: figures 490 \& 492), Das (2010: Pl. 70: figures 9a-b; depicted specimen originating from Assam, India; Indraneil Das, pers. comm., February 2020), Li 


\section{Plate 22}
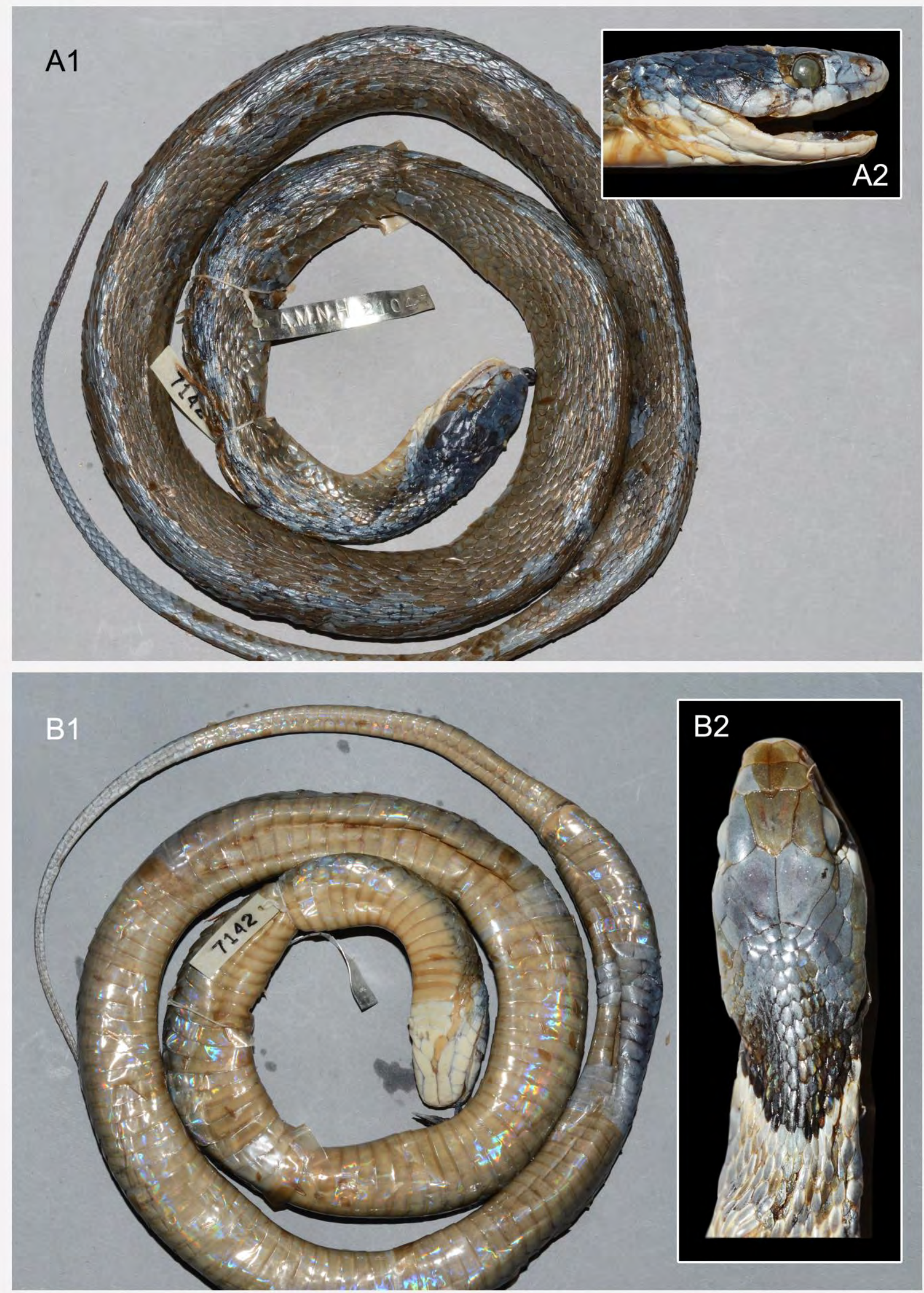

Figure 5. Rhabdophis helleri paratype (FMNH 7142): (A1) full body dorsal view, (A2) head lateral view, (B1) full body ventral view, and (B2) dorsal head regard the nuchal scalation (FMNH 42677) 


\section{Plate 23}
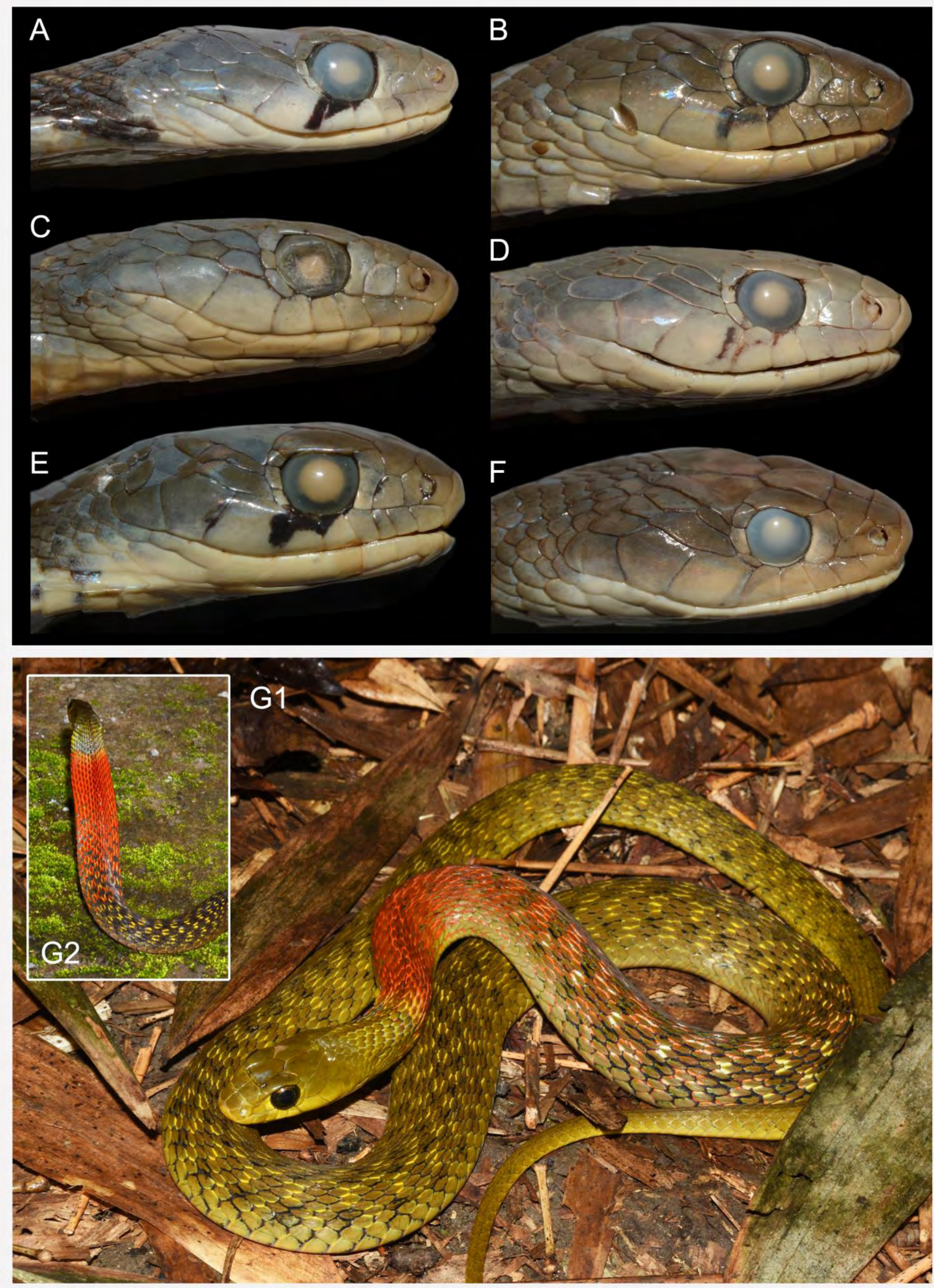

Figure 6. Lateral head colour pattern variation of adult Rhabdophis helleri (A) FMNH 42677, male; (B) NMW 22470, male; (C) ZMB 67298, male; (D) ZMB 11623, female; (E) NHMUK 1925.12.22.44, female; (F) NHMUK 1974.893, female; and (G1) a live adult (not collected) from Guangzhou city, Guangdong, China, (G2) with flattening its neck 
(2011: 220), Purkayastha et al. (2011: 215: figure D), Das (2012: 126), Majumder et al. (2012: 62: figure 3b), Messenger et al. (2012: 497), Purkayastha (2012: 37), Hecht et al. (2013: 548: figure 75), Kästle et al. (2013: 212: figure 3; 273: Pl. 44: figure 132; 523: figure 3; same specimen than in Schleich \& Kästle 2002), Purkayastha (2013: 94), Hasan et al. (2014: 133), Koushik (2015: 38-39 \& 147), Ziegler et al. (2015: 38: figure 70), Das \& Das (2017: 129), Lalremsanga \& Lalronunga (2017: 47), Bhattarai et al. (2018: 46: figure 36), Das (2018: 96; same specimen than in Das 2012), Purkayastha (2018: 12308: figure 39), Qi (2019: 175: figure 2), Shalauddin et al. (2019: 401), Zug \& Mulcahy (2019: 81: figure 15).

Holotype. Adult female, AMNH 20149 collected from "Tengyueh, 5500 feet altitude" (Tengchong, Province of Yunnan, People's Republic of China; $\left.25^{\circ} 01^{\prime} \mathrm{N}, 98^{\circ} 30^{\prime} \mathrm{E}\right)$, by R.C. Andrews and Edmund Heller on 24 April 1917.

Diagnosis. A large-sized species of the genus Rhabdophis characterized by the combination of (1) 19 (rarely 17, 18, 20 or 21) $19-17$ (rarely 15) dorsal scale rows; (2) dorsal scales narrowly but strongly keeled, scales of $1^{\text {st }}$ DSR smooth; (3) strong nuchal groove, well visible; (4) 2-8 distinctly enlarged, aligned nuchal scales; (5) VEN 157-178, SC 75-97, paired; (6) dorsum usually olive-green or dark greyish-green, or dark grey or brown, usually nearly uniform or chequered with black; (7) red hue on the neck present and usually conspicuous, although sometimes subdued; (8) dark subocular streak often totally absent or reduced to a few dots, or incomplete, or, more rarely, conspicuous; (9) when present, subocular streak shaped as a vertical bar or an incomplete triangle directed backwards, more or less faint and faded in its middle, rarely solid black and conspicuous, or as a broad comma; (10) venter cream or creamish-yellow anteriorly becoming on a short distance heavily dotted with dark grey backward.

Rhabdophis helleri can be easily distinguished from Rhabdophis subminiatus, as defined here, by the main following characters:

(1) the difference in total size, up to $130 \mathrm{~cm}$ in $R$. helleri vs. less than $80 \mathrm{~cm}$ in $R$. subminiatus;

(2) the number of ventrals: 157-178 $(x=$ $165.3, s d=3.6)$ vs. $132-145(x=136.8, s d=$ 2.6) in R. subminiatus;
(3) nuchal groove always present and strong vs. invisible;

(4) 3-8 (usually 5-7) enlarged, aligned paired nuchal scales vs. 0 aligned and enlarged scale (2 aligned pairs in only one specimen);

(5) no pale dorsolateral stripe or series of blotches vs. a pale dorsolateral stripe or a series of longitudinally aligned pale rectangular blotches usually present on $5^{\text {th }}-6^{\text {th }}$ dorsal scale rows in $R$. subminiatus;

(6) dark subocular streak often totally absent or usually reduced to a few dots, or incomplete, or, more rarely, conspicuous and directed downwards vs. most usually present and shaped as a narrow vertical bar or as narrow streak curved downwards or even forwards, rarely a broad vertical bar or as a thick streak in $R$. subminiatus.

(7) venter cream or pale creamish-yellow on a short distance anteriorly turning to heavily dotted or speckled with dark grey vs. venter always pale, i.e., cream or creamish-yellow, with usually a dark dot on the tips of each ventral in $R$. subminiatus.

The differences between $R$. helleri and $R$. siamensis and the new species described here, respectively, are given under the diagnoses of these species.

Description of species. Body rather robust, distinctly stout in large females, cylindrical; nuchal groove strong, well visible; head elongate, thick but somewhat flattened, distinct from the neck; snout elongate, slightly depressed, obtuse as seen from above, oblique seen in profile, 1.7-2.2 times greater than the diameter of the eye; nostrils lateral and directed laterally, small, crescent-shaped, piercing in the middle of the nasal; eye rather large, its diameter about 1.4-1.8 times greater than the distance between its lower margin and the margin of the lip, with a round pupil; tail long, rather thick at its base, cylindrical and tapering.

The longest examined specimen is 1,107 $\mathrm{mm}$ long (SVL $865 \mathrm{~mm}$; TaL $242 \mathrm{~mm}$; specimen NHMUK 1926.3.17.1, female). The longest male in our sample is $999 \mathrm{~mm}$ long (SVL 723 mm, TaL 276 mm; NMW 22468:1). According to the literature, $R$. helleri may reach a total length of 130 centimetres. This species is much larger than $R$. siamensis. In our sample of 51 specimens, 17 are over $800 \mathrm{~mm}$ in TL and even six are over $900 \mathrm{~mm}$ in total length.

Ratio TaL/TL: 0.219-0.286, with a strong sexual dimorphism. 
21-25 maxillary teeth on each jaw, gradually enlarging, the last two abruptly and very strongly enlarged, without diastema.

DSR: (17, 18)19(21) - 19 - (15)17 rows; scales strongly keeled with a narrow keel throughout the body; scales of $1^{\text {st }}$ DSR smooth. In our sample of 51 specimens, 6 have 17 scale rows around the neck, one has 18 rows, one 20 rows whereas another one has 21 scale rows. Only one specimen has 15 DSR before vent.

Number of aligned, paired enlarged scales on the nape: 3-8 (usually 5-7), well visible and most often regularly aligned.

VEN: 157-178 (plus usually 2 preventrals, rarely 1 or 3 ); $\mathrm{SC}$ : 75-97, paired, with a clear sexual dimorphism; cloacal plate divided. Ratio VEN/SC 1.68-2.17 ( $x=1.96, s d=0.09)$.

Position of the dorsal scale rows reduction from 19 to 17 DSR: VEN 82-93 $(x=87.4, s d=$ 2.5).

Complement of upper head scales complete including 2 internasals, 2 prefrontals, 2 supraoculars, 1 frontal, and 2 parietals. Rostral wider than high, barely visible from above; nasals pentagonal, elongate, much longer than high, vertically divided above and below the nostril, with the posterior part larger than the anterior scale; internasals subtriangular, in broad contact with each other, longer than wide, moderately narrowing anteriorly and abruptly truncated; 2 prefrontals, distinctly broader than long and 1.1-1.3 times longer than internasals; frontal large, shield-like, longer than wide and 2.2-2.4 times longer than prefrontal; 1 supraocular on each side, subtriangular, elongate, 2.0-2.4 times longer than wide, about as wide as internasals; parietals large and broad, 1.4-1.5 times longer than the frontal or suture between parietals 1.1-1.2 times longer than frontal; 1/1 loreal, pentagonal, not elongate, often higher than long or barely longer than high, in broad contact with the nasal; 1/1 preocular in all examined specimens; usually 3 small postoculars (very rarely 2, in four specimens, or 4 in six specimens); usually $8 / 8$ SL (7/8 in $1 / 51$ specimens only; $8 / 9$ or $9 / 8$ in $9 / 51$; and $9 / 9$ in $2 / 51$ ), the first five as long as high or slightly higher than long, $1^{\text {st }}$ and $2^{\text {nd }} \mathrm{SL}$ in contact with the nasal, $2^{\text {nd }}$ or $2^{\text {nd }}-3^{\text {rd }} \mathrm{SL}$ in contact with the loreal, usually $3^{\text {rd }}-5^{\text {th }} \mathrm{SL}$ touching orbit, also $4^{\text {th }}-6^{\text {th }}$ in 14 specimens, rarely $4^{\text {th }}-5^{\text {th }}$ (in 6 specimens) or $3^{\text {rd }}-4^{\text {th }}$ in the sole specimen with $7 \mathrm{SL}$ at left; $6^{\text {th }}-7^{\text {th }} \mathrm{SL}$ distinctly the largest; 2 anterior temporals (3 in only 2/102 occurrences), much elongate, narrowing anteriorly, lower one largest, followed by 2 or 3 posterior temporals ( 4 in $2 / 102$ occurrences), the most common total formula being $2+2$ or $2+3$ temporals; usually 10 infralabials, rarely 8 (in $1 / 102$ occurrences) or 9 (in 6/102 occurrences), first pair in contact, most usually $1^{\text {st }}-5^{\text {th }}$ IL (rarely $1^{\text {st }}-4^{\text {th }}$ ) in contact with anterior chin shields, $5^{\text {th }}, 6^{\text {th }}$ and $7^{\text {th }}$ IL largest; posterior chin shields narrower and longer than anterior ones.

Coloration of species. In preservative, the dorsal surface and sides are usually more green than in $R$. siamensis, namely olive-green or dark greyish-green, also olive-brown or dark greyishbrown (the same in life), not darker on the top than on the sides of the body; on the anterior half of the body, many dorsal scales are speckled with blackish-brown or black and also edged with cream or pale yellow (bright yellow in life) on their upper and lower margins, producing an irregularly speckled and vermiculate pattern; in adults, the posterior part of the body is rather uniform or finely speckled with black; 1 to 3 series of similar diffuse, rectangular, dark grey or black blotches on the upper and middle scale rows of the sides of the body, usually conspicuous on the forepart of the body, often absent or fainter on the posterior half; no black chevron just behind the occiput in adult; region of the nape, above and on its sides downwards up to the ventrals, uniform dark green or dark olive green, not darker than the background colour of the sides of the body; behind the nape, upper surface and sides of the neck distinctly coloured in deep red, vermilion-red or brick-red (turning to yellowish-grey or yellowish-brown in preservative) along a length equal to about 1.5 to 2.0 times the length of the head or 20 to 25 ventral scales before progressively vanishing; as in other species in this group, this pattern is due to the interstitial dorsal skin and edges of dorsal scales, or even a large part of the dorsal scales themselves, conspicuously tinged with red; in this species, this red hue may be absent in longpreserved specimens (and, in life, often subdued or nearly absent in larger specimens). The tail is as the dorsal surface in colour but nearly uniform.

The head is dark olive-green or dark greyish-green (the same in life); rostral, sides of the snout and 2 or 3 anterior supralabials paler than the upper head surface, i.e., olive-green or greyish-green; preocular, $3^{\text {rd }}$ or $4^{\text {th }}$ to $6^{\text {th }}$ or $7^{\text {th }}$ SL and postoculars, distinctly paler, are cream, pale greenish-cream or very pale grey, forming a 
distinct triangular area; $7^{\text {th }}$ and $8^{\text {th }}$ supralabials dark, coloured entirely or in their upper part as the upper head surface; dark subocular streak either entirely absent (in 22 specimens) or reduced to black dots just below the eye (in 10 specimens) or present as a faint bar or a hollowed out triangular marking (looking like "washed out" in its middle) (12 specimens) on the limit between the $5^{\text {th }}$ and $6^{\text {th }}$ SL or, in only 5 specimens, present as a solid, black or very dark grey marking, shaped as a vertical bar or, in only two of these five specimens, as a narrow triangle directed downwards and backwards. Infralabials, chin and throat are uniform cream or yellowishcream.

The venter is cream or yellowish-cream anteriorly, without any black dot on tips of ventrals (dots present in only 1 of 51 examined specimens); at about one or two head length, the venter becomes heavily speckled or vermiculate with dark grey or dark greyish-brown, producing a dark powdered venter (diagnostic character). Under surface of tail dark cream or yellowishcream, heavily powdered with dark grey or dark greyish-brown as the venter.

Juvenile specimens are coloured as adults but their pattern is much more contrasted and is similar to the pattern seen in Rhabdophis siamensis, except for the powdered venter which is never present in $R$. siamensis. Rectangular black blotches are usually more conspicuous on the body. The head is usually dark green or dark greenish-grey above, paler on the sides of the snout; the very pale area on the middle supralabials is present; a narrow black supraocular streak is usually present, shaped as a more or less wide vertical bar; the nape is deep black, bordered behind with a more or less extensive area of bright yellow, followed by the bright red upper surface and sides of the neck.

Sexual dimorphism. The base of the tail is distinctly bulging in adult males. A sexual dimorphism is expressed in the sole following character: Number of subcaudal scales: males: 82-97 $(x=90.1, \quad s d=4.7)$; females: $75-83$ $(x=80.1, s d=3.4)$. A Mann-Whitney $U$-test (one-tailed) gives a level of difference between the samples significant at $\mathrm{p}<0.001(U=12.0$; $\mathrm{z}$ score $=-4.53718)$.

Distribution. (Fig. 9). Nepal: Definitely recorded from this country by Bhattarai et al. (2018) from Ghodemasan area, Parsa National Park, southern central Nepal (see below). Bhutan: Cited by Wangyal (2019). India: Present throughout Northeast
India: states of Sikkim, West Bengal, Assam, Meghalaya, Mizoram and Nagaland (Whitaker \& Captain 2004; our material). Bangladesh: Northwest: Rajshahi Division; northeast: Sylhet Division; east and southeast: Chittagong Division (Hasan et al. 2014; Ahmad et al. 2015). Myanmar: North, centre and east, in the following states or regions: Bago, Chin, Kachin, Kayah, Mandalay, Sagaing, and Shan (Doria et al. 2013; Liu et al. 2021). People's Republic of China: Provinces of Yunnan, Sichuan, Guizhou, Guangxi Zhuang, Guangdong, Hong Kong S. A. R., and Fujian (Zhao et al. 1998; Zhao 2006; Liu et al. 2021). Vietnam: provinces of Bac Giang, Bac Kan, Bac Ninh, Cao Bang, Ha Giang, Hai Duong, Ha Tay, Hoa Binh, Lang Son, Lào Cai, Phu Tho, Quang Ninh, Son La, Vinh Phuc, and Yen Bai; southern limit uncertain. Laos: Recorded only from the extreme north of the country: Phôngsali Province (our material). Thailand: Recorded only from the extreme north of the country: northern districts of the provinces of Chiang Mai, Chiang Rai and Mae Hong Song (our material and Sjon Hauser's data; pers. comm., February 2020).

Bhattarai et al. (2018) confirmed the occurrence of Rhabdophis helleri in Nepal. Previously, Schleich \& Kästle (2002) and Kästle et al. (2013) had recorded this species from central Terai, in Chitwan National Park, Chitwan District, Narayani Zone. However, the same and sole specimen depicted by these authors is quite unusual with its deep black head and nape followed by a white collar. We could not examine this specimen but additional pictures, kindly communicated by $\mathrm{H}$. $\mathrm{H}$. Schleich, show that its dorsal surface is heavily spotted with small, white blotches, a pattern not known in other specimens of $R$. helleri. In contrast, the specimen depicted in Shah \& Tiwari (2004: 188) and Sharma et al. (2013: 65) originates from Phang-Nga Province, Thailand, and is a typical $R$. siamensis (Frank Tillack, pers. comm., March 2020).

As stated above, we identified a fourth group of specimens that we could not refer to any of the species described above. Therefore, we refer them to a new species that describe as:

Rhabdophis confusus sp. nov. [urn:1sid:zoobank.org:act:A20EC3BA-3AB7-4352-8DD881D49014609F]

(Figs. 7-9; Tables 2, 3)

Holotype. ZMB 29237, adult female from 
"Hainan", now Hainan Island and Province, People's Republic of China, deposited by Mr. Schoede; no date of collect given.

Paratypes $(n=2)$. FMNH 6679 and FMNH 6680, adult females, from "Hainan Island", People's Republic of China; deposited by C.H. Pope.

Other material. Based on Zhao et al. (1998): 25 specimens (8 males and 17 females).

Taxonomic history. Schmidt (1927a) provided a description of specimens from Hainan Island, a province of the People's Republic of China, under the combination Natrix subminiata. This author did not refer specimens from this island to any subspecies. We have shown above that the population of Hainan represent a distinct species. To this new species, we here refer the following specimens: (1) three individuals examined by us, all referred to the series of name-bearing types, and (2) 25 specimens described by Shi et al. (2011) and Zhao et al. (1998). Altogether, we present the main scalation data of 25 specimens. We could not examine specimens mentioned by Schmidt (1927).

The holotype of Rhabdophis confusus sp. nov. is one of the Hainan unnumbered original syntypes of Natrix subminiata siamensis. Although these specimens share several scalation characters with Rhabdophis siamensis of the mainland as defined here, they also differ by other diagnostic characters.

Iconography in the literature. Rhabdophis confusus sp. nov. has been depicted in the literature in Shi et al. (2011: Pl. XXII: figure 117).

Diagnosis. A medium-sized species of the genus Rhabdophis endemic to Hainan Island, characterized by the combination of (1) $19-19$ - 17dorsal scale rows; (2) dorsal scales narrowly but strongly keeled, scales of $1^{\text {st }}$ DSR smooth; (3) a moderate nuchal groove present, well visible; (4) 4-8 distinctly enlarged, aligned paired nuchal scales; (5) VEN 144-158, SC 5679 paired; (6) dorsum olive-green or dark greyish-green, dark greyish-brown or dark reddish-brown, distinctly chequered with diffuse, black blotches; (7) red hue on the upper part and sides of the neck faint or absent; (8) dark subocular streak totally absent; (10) venter uniform cream or pale creamish-yellow, without dark dots on the tips of ventrals but with outer fifth or quarter of ventrals heavily mottled with dark grey.
Rhabdophis confusus sp. nov. differs from Rhabdophis siamensis by the following characters:

(1) the number of ventral plates (both sexes together; based on examined specimens and on values given in Zhao et al. 1998): 144-158 ( $x=$ $152.1, s d=3.0)$ in $R$. confusus sp. nov. vs. 137$156(x=146.0, s d=5.4)$ in $R$. siamensis. These values suggest a large overlap in the numbers of ventrals but a Mann-Whitney $U$-test (one-tailed) gave a level of difference between the samples significant at $\mathrm{p}<0.001(\mathrm{U}=361.5 ; \mathrm{z}$-score $=$ 5.0998);

(2) a shorter tail, expressed by the ratio Tail length/Total length (both sexes together; based on examined specimens and on values given in Zhao et al. 1998): 0.191-0.269 $(x=0.235$, sd $=$ $0.019)$ vs. $0.238-0.303(x=0.263, s d=0.015)$ in $R$. siamensis. These values suggest a large overlap but a Mann-Whitney $U$-test (one-tailed) gave a level of difference between the samples significant at $\mathrm{p}<0.001(\mathrm{U}=121.0 ; \mathrm{z}$-score $=$ 5.0367);

(3) the black subocular streak: absent in all examined specimens of Rhabdophis confusus sp. nov. vs. streak always present, conspicuous and triangular in $R$. siamensis;

(4) the red coloration of the skin of the upper surface of the neck and anterior part of the body: very subdued or absent vs. present and conspicuous in $R$. siamensis;

(5) venter pale, cream or pale grey, uniform except the quarter or fifth outer part of each ventral plate heavily mottled with dark grey vs. venter cream or creamish-yellow without dark dots on the tips of ventrals, or only along the anterior part of the venter in $R$. siamensis.

Lastly, the general dorsal pattern is similar in these two species, although the background colour is darker in Rhabdophis confusus sp. nov.

Rhabdophis confusus sp. nov. differs from Rhabdophis helleri by the following characters:

(1) the number of ventral plates: 144-158 ( $x$ $=152.1, s d=3.0$ ) in Rhabdophis confusus sp. nov. vs. $157-178(x=165.3, s d=3.6)$ in $R$. helleri;

(2) neck faintly red or of same colour than the dorsum in $R$. confusus sp. nov. vs. the upper part and sides of the neck usually conspicuously tinged with red, rarely faint;

(3) venter pale, i.e., cream or pale greyishbrown, without dark dots on the tips of ventrals but with outer fifth or quarter of ventrals heavily mottled with dark grey vs. venter cream or pale creamish-yellow on a short distance becoming 


\section{Plate 24}
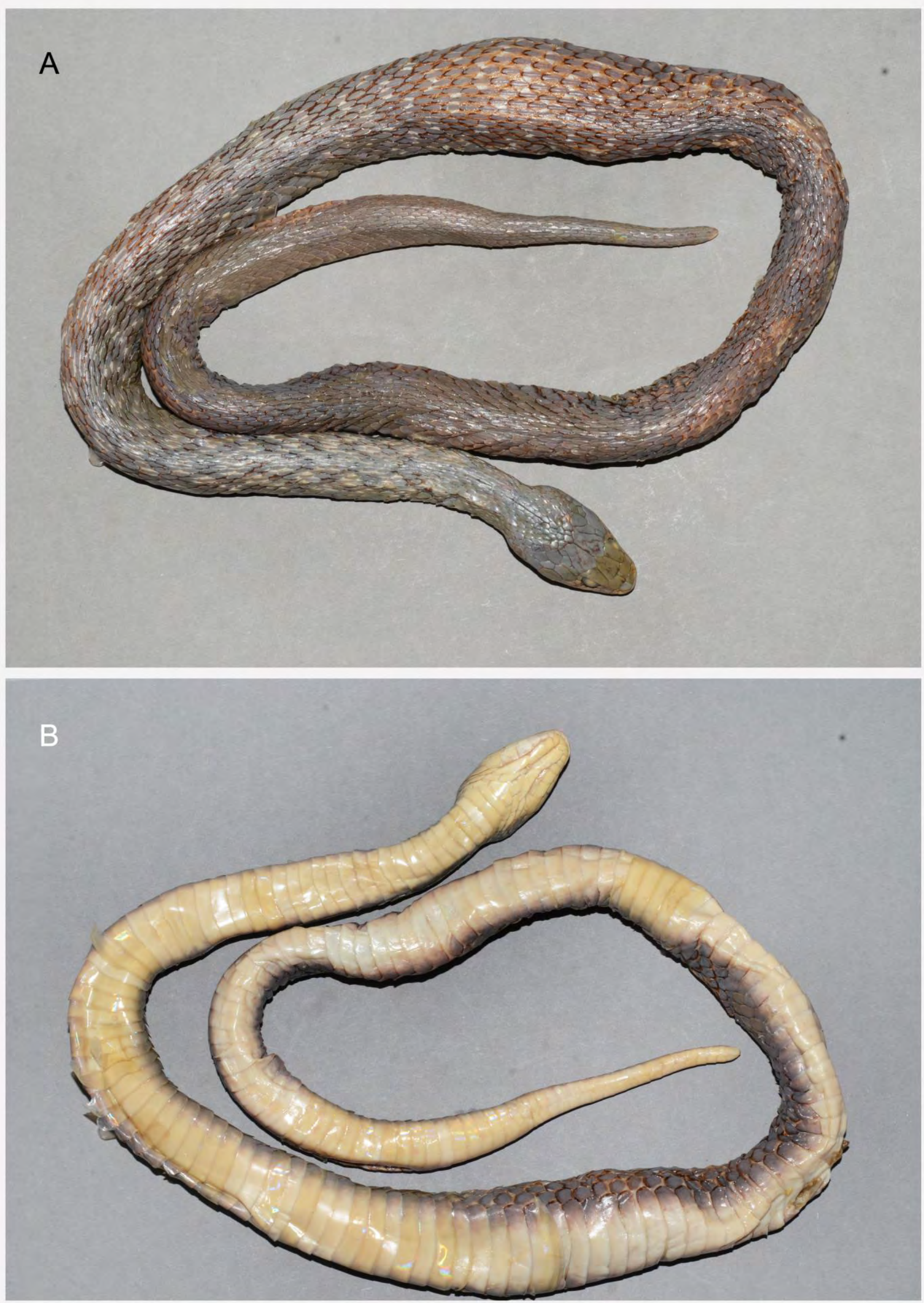

Figure 7. Rhabdophis confusus sp. nov. holotype (ZMB 29237, adult female) from Hainan Island, China: full body (A) dorsal view and (B) ventral view 


\section{Plate 25}
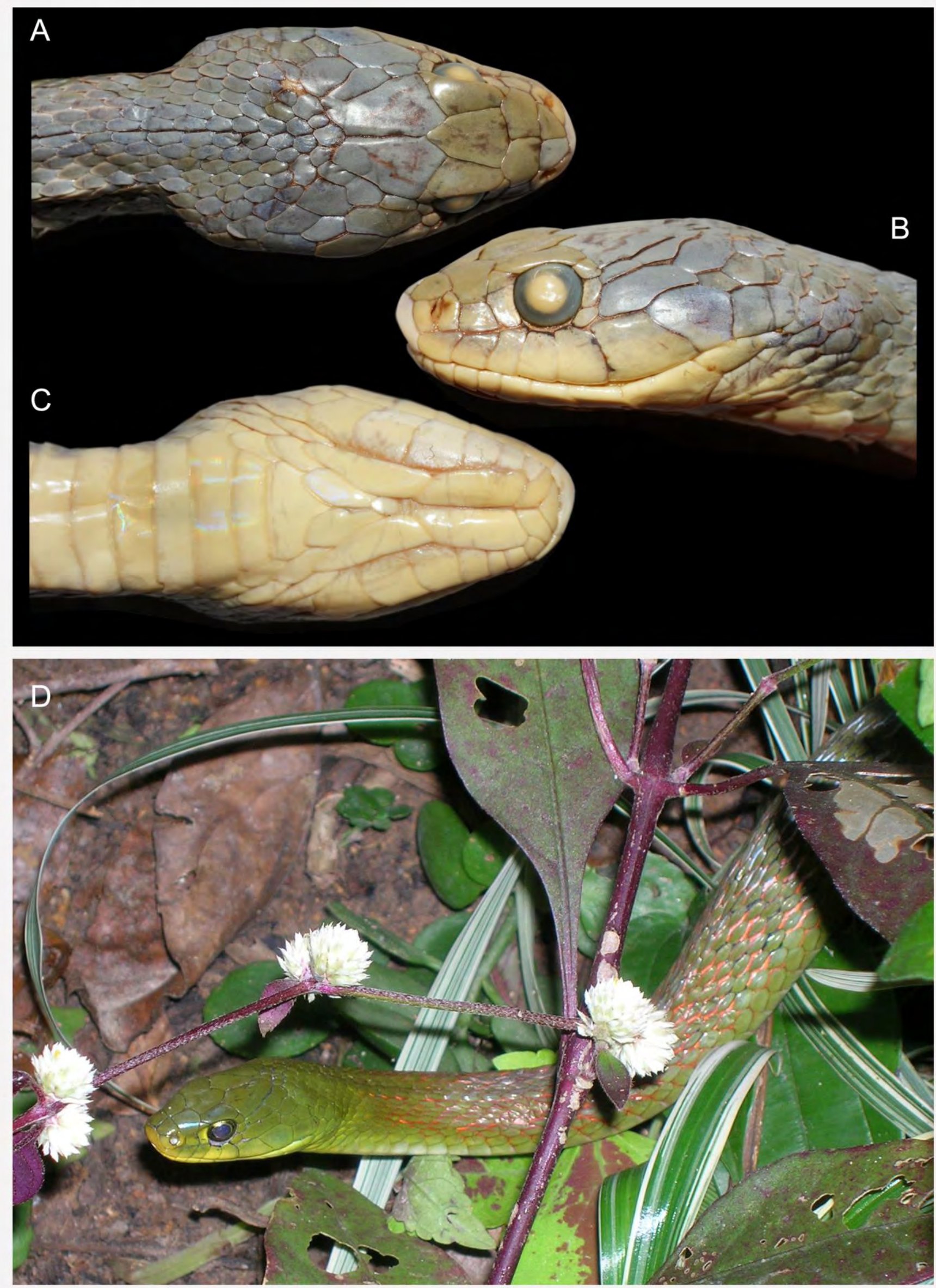

Figure 8. Rhabdophis confusus sp. nov. holotype (ZMB 29237, adult female) from Hainan Island, China: head (A) dorsal view; (B) lateral view; (C) ventral view; and (D) a live adult (not collected) from Sanya, Hainan Island, China; (C) Photo: W. Scott Lupien 
shortly after the head heavily dotted or speckled with dark grey posteriorly.

Although $R$. confusus sp. nov. differs from $R$. helleri by only a few significant characters, they are constant and easy to notice.

Lastly, Rhabdophis confusus sp. nov. differs from Rhabdophis subminiatus by the following characters:

(1) a moderate, well visible nuchal groove bordered with 4-8 distinctly enlarged, aligned paired nuchal scales in Rhabdophis confusus sp. nov. vs. nuchal groove not visible and no enlarged (exceptionally slightly enlarged) nuchal scales in R. subminiatus;

(2) the number of ventral plates: 144-158 ( $x$ $=152.1, s d=3.0)$ in Rhabdophis confusus sp. nov. vs. $132-145(x=138.8, s d=2.6)$;

(3) red hue on the upper part and sides of the neck faint or absent in Rhabdophis confusus sp. nov. vs. upper surface and sides of the neck and anterior part of the body extensively tinged with bright vermilion-red or coral;

(4) dark subocular streak totally absent in Rhabdophis confusus sp. nov. vs. a dark brown or black subocular streak usually present;

(5) venter uniform without dark dots on the tips of ventrals but with outer parts of ventrals heavily mottled with dark grey in Rhabdophis confusus sp. nov. vs. venter always pale, i.e., cream or creamish-yellow, with a dark dot on the tips of each ventral.

As Rhabdophis confusus sp. nov. obviously belongs to the species complex of Rhabdophis subminiatus, we will not compare it with other species of the genus Rhabdophis except to two species of the genus present in south-eastern China and Vietnam. Rhabdophis confusus sp. nov. differs from Rhabdophis adleri Zhao, 1997 by the main following characters:

(1) a different dorsal pattern, dorsum distinctly chequered with diffuse, black blotches in Rhabdophis confusus sp. nov. vs. olive green with 40-70 short, yellow dorsolateral crossbars on each side in $R$. adleri;

(2) 4-8 distinctly aligned, enlarged paired nuchal scales in Rhabdophis confusus sp. nov. vs. about 12 paired nuchal scales;

(3) 68-73 subcaudals in Rhabdophis confusus sp. nov. vs. 76-87 subcaudals.

Rhabdophis confusus sp. nov. differs from Rhabdophis guangdongensis Zhu, Wang, Takeuchi \& Zhao, 2014 by:

(1) 19 dorsal scale rows at midbody in Rhabdophis confusus sp. nov. vs. 15 rows in $R$. guangdongensis;
(2) 8 supralabials in Rhabdophis confusus sp. nov. vs. 6 in $R$. guangdongensis;

(3) 144-158 ventral plates in $R$. confusus vs. 126 ;

(4) dorsum distinctly chequered with diffuse, black blotches in Rhabdophis confusus sp. nov. vs. dorsum with narrow black crossbars.

Lastly, Rhabdophis confusus sp. nov. differs from Rhabdophis chiwen Chen, Ding, Chen \& Piao in Piao, Chen, Wu, Shi, Takeuchi, Jono, Fukuda, Mori, Tang, Chen \& Ding, 2020 by:

(1) 19 dorsal scale rows at midbody in Rhabdophis confusus sp. nov. vs. 15 rows in $R$. chiwen;

(2) 8 supralabials in Rhabdophis confusus sp. nov. vs. 5 in $R$. chiwen;

(3) a different dorsal coloration, distinctly chequered with diffuse, black blotches in Rhabdophis confusus sp. nov. vs. uniform in $R$. chiwen; the coloration of the venter is also different, uniform cream or pale creamishyellow in $R$. confusus sp. now vs. nearly entirely dark brownish-red in R. chiwen; see Piao et al. (2020).

Description of holotype. An adult female in good condition but with the tail incomplete. SVL $652 \mathrm{~mm}$, TaL > $50 \mathrm{~mm}$, incomplete, TL > $702 \mathrm{~mm}$. Body elongate, cylindrical and robust; head elongate (about $4.9 \%$ of SVL), ovoid, rather broad and distinct from the neck; a relatively weak but distinct nuchal groove, edged with 8 aligned, enlarged paired nuchal scales on each side; snout elongate, obtuse as seen from above, oblique seen in profile, 1.7 times longer than the horizontal diameter of the eye; nostrils lateral, small, vertically crescentshaped, piercing in the middle of the nasal; eye large, 1.3 times greater than the distance between its lower margin and the margin of the lip.

DSR $19-19-17$, distinctly and strongly keeled, scales of the $1^{\text {st }}$ DSR smooth.

VEN 154 (+ 2 preventrals); $\mathrm{SC}>18$, tail largely incomplete; cloacal plate divided.

Arrangement of upper head scales complete including 2 internasals, 2 prefrontals, 2 supraoculars, 1 frontal, and 2 parietals. Rostral wider than high, barely visible from above, not inserting between internasals; nasals pentagonal, elongate, 1.9 times longer than high at the level of the nostril, vertically divided by the nostril and a suture below it, with the postnasal larger than prenasal; internasals subtriangular, 
relatively small, in broad contact with each other, as long as wide, moderately narrowing anteriorly and abruptly truncated; 2 prefrontals, pentagonal, distinctly wider than long and 1.4 times longer than internasals; frontal large, hexagonal, shield-like, posterior edges pointing backwards, 1.15 times longer than wide and 2.1 times longer than prefrontals; $1 / 1$ supraocular, subtriangular, elongate, 1.8 times longer than wide, wider on their posterior part, about as wide as internasals, a little bit more than half as wide as the frontal; parietals large and broad, about 1.6 times longer than the frontal and their suture 1.15 times longer than frontal, not abruptly truncated posteriorly, their distal end separated by a large scale; 1/1 loreal, pentagonal, not elongate, often higher than long or barely longer than high, in broad contact with the nasal; $1 / 1$ preocular, large and tall, not reaching the frontal; no presubocular; $3 / 3$ small postoculars; $8 / 8 \mathrm{SL}, 1^{\text {st }} / 1^{\text {st }}$ elongated, in contact with the nasal, $1^{\text {st }}-2^{\text {nd }} / 1^{\text {st }}-2^{\text {nd }} S L$ in contact with the loreal, $3^{\text {rd }}-5^{\text {th }}$ SL entering orbit, $6^{\text {th }}-7^{\text {th }} \mathrm{SL}$ distinctly the largest on both sides; 2 / 2 anterior temporals, lower one much elongate and largest, followed by $3 / 3$ posterior temporals, relatively small; 10/10 infralabials, first pair in contact, $1^{\text {st }}-6^{\text {th }} / 1^{\text {st }}-5^{\text {th }}$ in contact with anterior chin shields, $5^{\text {th }}-6^{\text {th }} / 6^{\text {th }}-7^{\text {th }}$ IL largest; posterior chin shields narrower but longer than anterior ones.

Coloration of holotype. In preservative, the dorsal surface and sides are dark brownish-grey, with scales distinctly edged or speckled with cream on the anterior half of the body, more uniform posteriorly; some irregular and faint dark grey areas but not producing a chequered pattern; a large area behind the neck mottled with pinkish-cream (probably vermilion-red in life). The tail is uniform brownish-grey.

The head is dark grey, not darker than the body; rostral, sides of the snout and supralabials pale yellowish-grey, paler than upper head surface; a very small dark blotch on the upper posterior corner of the $3^{\text {rd }} \mathrm{SL}$ at right; no dark subocular streak but limit between $5^{\text {th }}$ and $6^{\text {th }}$ SL narrowly edged with black. The infralabials, chin and throat are uniform pale yellow and devoid of any marking. The venter is uniform pale yellow, with only the tip and outer part of each ventral clouded with dark lead-grey, without distinct dark spots. Lower surface of tail uniform yellowish-cream with the tip and outer part of each subcaudal clouded with lead-grey.

Variation and description of the species. Main characters of the holotype and of the two paratypes, as well as variation of these same characters in specimens listed in Zhao et al. (1998) and Shi et al. (2011) are listed in Table 2. Other main qualitative characters of this species are as follows: Maximum known length: 810 mm (female) according to Schmidt (1927a). The longest specimen examined by us is $745 \mathrm{~mm}$ long (SVL $580 \mathrm{~mm}$, TaL $165 \mathrm{~mm}$, female, specimen FMNH 6679). Longest known male: $603 \mathrm{~mm}$ (SVL $441 \mathrm{~mm}$, TaL $162 \mathrm{~mm}$; specimen MVZ 23733).

Table 2. Selected body characters of the type series of Rhabdophis confusus sp. nov. (mainly after Zhao et al. 1998, Shi et al. 2011, and Jin-Long Ren pers. comm., Sept 2021); F = female; L = left; R = right; ? = unknown.

\begin{tabular}{lcccc}
\hline \multirow{2}{*}{ Character } & \multicolumn{3}{c}{ Rhabdophis confusus sp. nov. } & \multirow{2}{*}{ Based on } \\
\cline { 2 - 4 } & Holotype & \multicolumn{2}{c}{ Paratypes } & literature \\
\cline { 2 - 4 } Sex & ZMB 29237 & FMNH 6679 & FMNH 6680 & $?$ \\
SVL (in mm) & F & F & F & 555 max \\
Tail length (TaL, in mm) & 652 & 580 & 550 & 162 max \\
TaL/total length (TL) & $?$ & 165 & 164 & $0.191-0.269$ \\
Ventrals (VEN) & $?$ & 0.221 & 0.230 & $144-158$ \\
Subcaudals (SC) & 154 & 153 & 150 & $56-79$ \\
Postoculars (L/R) & $?$ & 68 & 73 & $3 / 4$ \\
Supralabials (L/R) & $3 / 3$ & $3 / 3$ & $3 / 3$ & $8-9$ \\
Supralabials touch orbit (L/R) & $8 / 8$ & $8 / 8$ & $8 / 8$ & $3-5 / 4-6$ \\
Anterior temporals (L/R) & $3-5 / 3-5$ & $3-5 / 3-5$ & $3-5 / 3-5$ & $2-3$ \\
Infralabials (L/R) & $2 / 2$ & $2 / 3$ & $2 / 2$ & $?$ \\
Nuchal groove & $10 / 10$ & $10 / 10$ & $10 / 9$ & $?$ \\
Nuchal scales & moderate & weak & moderate & $?$ \\
Dorsal colour & 8 & 4 & 5 & $?$ \\
Dorsal colour pattern & olive & olive & olive & $?$ \\
Subocular streak & chequered & chequered & chequered & $?$ \\
Ventral colour pattern & absent & absent & absent & $?$ \\
\hline
\end{tabular}


Ratio Tal/TL 0.191-0.269.

The body is rather robust, cylindrical; head ovoid, elongate, moderately distinct from the thick neck; snout long; about 1.7-2.0 times as long as the eye diameter; nostril vertically crescent-shaped, elongate, piercing the upper side of nasal at the level of the division of the scale; eye large, its diameter 1.3-1.5 times the distance between the edge of the lip and its lower margin, with a round pupil; tail long and tapering.

Dorsal scales in $17-19-17$ rows; scales ovoid, strongly keeled; ventral plates 144-158, not angulate; subcaudal scales 56-79, all paired; cloacal plate divided.

Arrangement of upper head scales complete in all known specimens. Rostral wider than high, visible from above; nasal pentagonal, vertically divided, elongate1.8-1.9 times longer than high, vertically divided below the nostril, with the postnasal larger than the prenasal; internasals subtriangular, moderately narrowing anteriorly and abruptly truncated, in broad contact with each other; prefrontals pentagonal, distinctly broader than long, 1.3-1.4 times longer than internasals; frontal hexagonal, large, shield-like, 1.1-1.2 times longer than wide and 2.0-2.2 times longer than prefrontals; 1 supraocular on each side, undivided, subtriangular, 1.8-2.0 times longer than wide, narrower than internasals and about half as wide as frontal; parietals large and broad, 1.5-1.6 times longer than the frontal; 1 small loreal on each side, subrectangular or pentagonal, not longer than high, in broad contact with the postnasal; 1 preocular in all examined specimens, large and tall; no presubocular; 3 (rarely 4) postoculars, small and subequal; 8 (rarely 9) supralabials, $1^{\text {st }}$ and $2^{\text {nd }} \mathrm{SL}$ in contact with the nasal, $3^{\text {rd }}-5^{\text {th }}$ (rarely $4^{\text {th }}-6^{\text {th }}$ ) entering orbit, $6^{\text {th }}-7^{\text {th }}$ SL largest; on each side, 2 or $1 / 1+1$ (exceptionally 3 ) anterior temporals, lower one elongate, followed by 2 or 3 (exceptionally 4 ) posterior temporals, the common formula being $2+3$ temporals; 9 or 10 infralabials, first pair in contact behind the small mental scale, $1^{\text {st }}-5^{\text {th }}$ or $1^{\text {st }}-6^{\text {th }}$ infralabials in contact with anterior chin shields, $5^{\text {th }}-6^{\text {th }}$ or $6^{\text {th }}-7^{\text {th }}$ the largest; posterior chin shields about 1.2 times longer than anterior ones.

Coloration of species. The dorsal surface is dark grey, dark greyish-brown or dark reddishbrown (similar in preservative and life); many dorsal scales irregularly edged and speckled with cream or pale yellow, more visible on the forepart of the body; a series of very dark grey or black dorsolateral blotches, more or less visible; one or two series of similar blotches, diffuse, dark grey or black on the upper and middle scale rows of the sides of the body producing a mottled dorsum; region of the neck, above and on its sides downwards up to the ventrals of same colour than the dorsum or mottled with some red hue (pink in preservative), the red part being never conspicuous. The tail is as the dorsal surface in nearly uniform colour.

The head is dark grey, dark brown or brownish-grey; rostral, sides of the snout and $1^{\text {st }}$ and $2^{\text {nd }}$ supralabials distinctly paler than the upper head surface, i.e., pale yellowish-grey or pale yellowish-brown; $3^{\text {rd }}$ to $5^{\text {th }}$ or $6^{\text {th }}$ supralabials and postoculars still paler, i.e., pale yellowish-cream, or like other supralabials; subocular streak always absent. Infralabials, chin and throat are uniform cream or yellowishcream.

The venter is uniform pale, namely cream or pale greyish-brown, without dark dots on the tips of ventrals but with outer fifth or quarter of ventrals heavily mottled with dark grey. Lower surface of tail uniform yellowish-cream with the tip and outer part of each subcaudal clouded with lead-grey.

Sexual dimorphism. We could not identify any dimorphism including Tal/TL ratio.

Etymology. The specific nomen is the Latin adjective confusus $(-a,-u m)$, here in masculine gender, meaning "confused" or "mixed", based on the confusion of this species with Rhabdophis siamensis.

We suggest the following common names: Hainan Island keelback snake (English), Rhabdophide de Hainan (French), Hainan Rothals-Wassernatter (German), and 拟红脖颈槽蛇, Nĩ Hóng Bó Jǐng Cáo Shé (Chinese).

Distribution. (Fig. 9) People's Republic of China: Hainan Island. This species has been recorded from the following localities: Dialuo Shan (Mt. Dialuo); "Dwa-bi", now Da Bian; "Fan-heang", now Fan Xiang; "Kachek", now Qionghai County; "Nodoa", now Nada, Zhanxian County; Sanya, Sanya County, Wuzhi Shan (Mt. Wuzhi), Wuzhishan City (based on Zhao et al. 1998 and our material). 


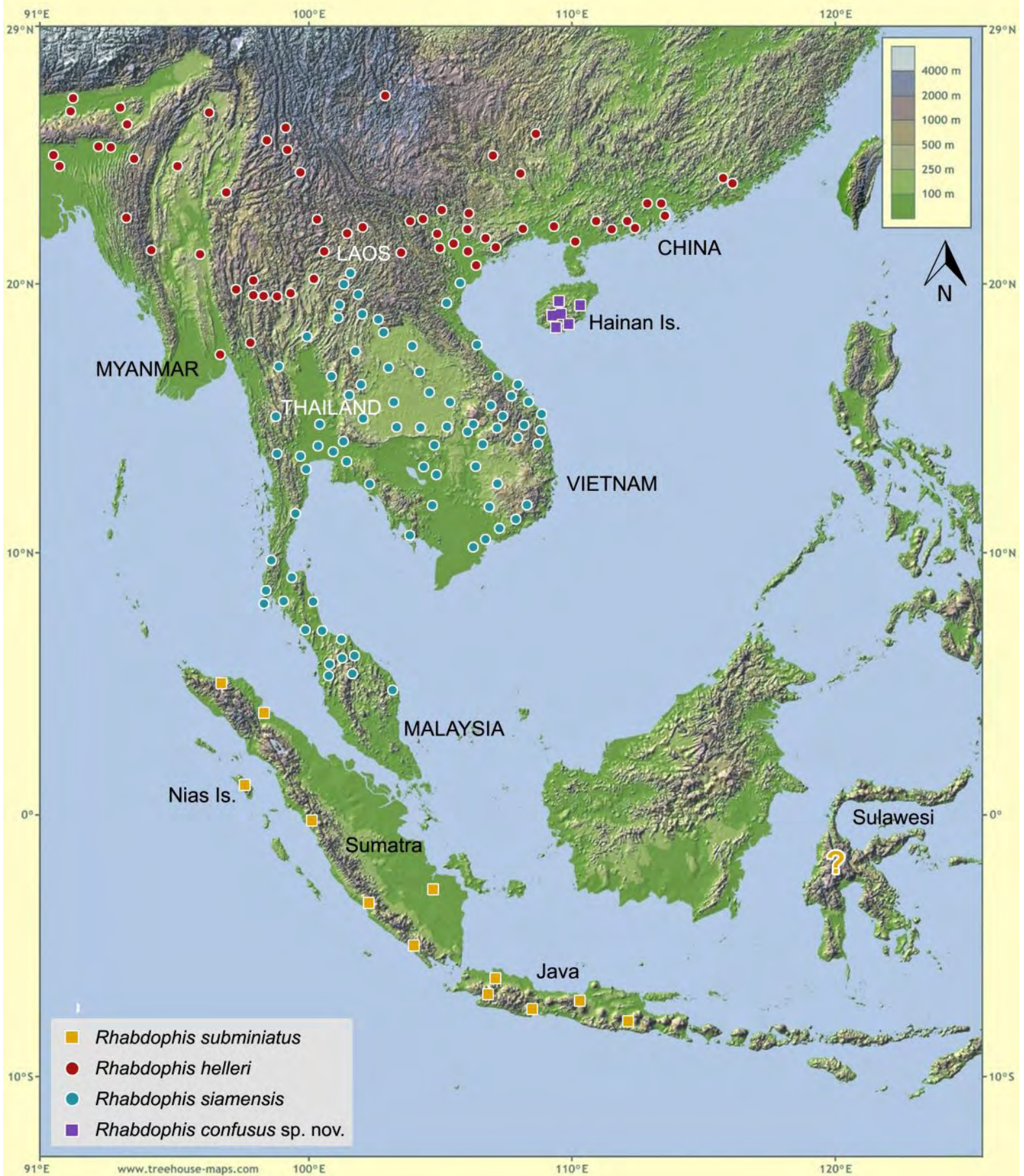

Figure 9. Distribution map of the species Rhabdophis subminiatus (yellow squares), $R$. helleri (red circles), $R$. siamensis (blue circles), and Rhabdophis confusus sp. nov. (purple squares)

\section{Discussion}

Comparison between morphological results and molecular phylogenies: Unfortunately, genetic data is not available for all the populations dealt with in this paper. Nevertheless, Takeuchi et al. (2018: 10223: figure 2) published a phylogenetic tree that clearly showed the presence of two subclades under the combination Rhabdophis subminiatus: one subclade includes a specimen from Laos and another one from Vietnam; the second subclades includes two specimens from Thailand. Takeuchi et al. (2018) pointed out the substantial genetic divergence that occurs between populations currently referred to $R$. subminiatus. Thanks to the courtesy of Akira Mori and Hirohiko Takeuchi (pers. comm, April 2020), the unpublished collection localities of 
these specimens are as follows: specimens HT0344 and HT0345, which together form one of the subclades containing " $R$. subminiatus_2" and "R. subminiatus 3", originate from Khao Sabap, Kwian Hak, Khlung District, Chanthaburi Province, in south-eastern Thailand; these specimens were collected in the range of $R$. siamensis. In contrast, specimen HT0680 ("R. subminiatus_4" in the tree) was collected at Ban Nhop Village, Chieng Bom Com, Thuan Chan District, Son La Province, Vietnam. Together with specimen HT0267 (" $R$. subminiatus_1" in the tree), from "Laos", without specified locality, it forms the second subclade. Son La Province, located in northwestern Vietnam, is full in the range of $R$. helleri. Based on these records, the molecular phylogeny published in Takeuchi et al. (2018) thus confirmed the separation of populations here referred to $R$. siamensis and $R$. helleri at specific level.

Liu et al. (2021) specifically addressed the intraspecific taxonomy of the $R$. subminiatus complex while the present paper was under review. These authors based their analysis on external morphological characters, mitochondrial DNA (mtDNA)-based phylogeny, single-nucleotide polymorphism (SNP)-based phylogeny, and population structure analysis. The phylogenetic analyses uncovered two highly distinct lineages separated by a large genetic distance of $10.6-11 \%$ (uncorrected genetic pdistances depending on the gene), as shown on their tree published on figure 1, page 1375 . Based on the maps associated with the trees of figures 1 and 2 of Liu et al. (2021), clade A corresponds to the populations of northern Myanmar, southern China and northern Vietnam whereas Clade B of their tree includes populations of central Myanmar, Thailand, extreme southern Yunnan, central and southern Vietnam, as well as populations of Indonesia and Hainan Island.

Liu et al. (2021) referred Clade A to the taxon Rhabdophis subminiatus helleri that they elevated to full species status. Our morphological data confirm the distinctiveness at species level of this taxon. However Liu et al. (2021) recovered two subclades, named A1 and A2. This latter clade includes specimens from Yunnan (south-western China) and Yunnan, west of those referred to the main subclade A1. In our sample of examined specimens, we could not identify any morphological difference, either in scalation and morphometry, or in pattern between specimens referable to these subclades. We do not recognize any taxonomic rank to Liu et al.'s subclades.

The case of Clade B is more complex. This clade, as recovered in the tree published by Liu et al. (2021: figure 1), corresponds to the former subspecies Rhabdophis subminiatus subminiatus. The phylogenetic tree shown in figure 1 of these authors is divided into two main subclades, one of which is itself divided into two lineages. Liu et al. (2021) did not give a taxonomic rank to these subclades or even mentioned their morphological differences; these authors identified all of them as Rhabdophis subminiatus. However, we can here refer each of these three lineages to three of the four species defined in the present paper. The subclade here designated as "B1", divided into two lineages, named here as "L1" and "L2", contains specimens from central Vietnam, southern Yunnan (China), southern Myanmar, Thailand ("L1") and Indonesia "L2). Lineage "L1", including only specimens from the mainland, corresponds to Rhabdophis siamensis. We refer this clade to this latter species based on the type locality of $R$. siamensis and the range of this species as defined here. The range depicted on figure 1 of Liu et al. (2021) nearly fully agrees with our own range of $R$. siamensis, except the population of Hainan Island. Lineage "L2", sister taxon of "L1", includes only two specimens from Indonesia; therefore it corresponds to Rhabdophis subminiatus as defined in the present paper. Although lineages "L1" and "L2" are not as well strongly supported as other clades, with branch support indices of 0.78 (bootstrap probabilities) /84 (posterior probabilities), the morphological differences between specimens of these two taxa plea for a distinct taxonomic status. Lastly, clade "B2" of Liu et al. (2021), sister taxon of the subclade "L1 + L2", comprises two specimens from Hainan Island. According to our morphological analyses, we have here shown that the population of Hainan Island deserves a distinct taxonomic status.

Based on the tree of Liu et al. (2021), one may consider the three lineages of their Clade B as subspecies of $R$. subminiatus. However, as these taxa are fully diagnosable and geographically separated, we consider them at full species level. As a summary, the phylogenetic tree, based on molecular analyses, confirms that the Rhabdophis subminiatus complex of species is divided into two widely 
divergent clades corresponding to Rhabdophis helleri and the complex of $R$. subminiatus, respectively. Liu et al. (2021) showed that the main clade of $R$. subminiatus contains three distinct lineages comprising specimens from the Indochinese Region, Indonesia and Hainan Island, respectively. The recognition of these lineages based on molecular analyses confirm the validity of Rhabdophis subminiatus, $R$. siamensis and $R$. confusus as defined here based on morphological characters.

Liu et al. (2021: figure 1) placed two specimens from the regions of Ayeyarwady (specimen CAS 212026/GP 791) and Yangon (CAS 230391/GP 793), in southern Myanmar, in the range of the mainland part of their Clade B, namely Rhabdophis siamensis. In our material, we examined specimens from southern Shan State in Myanmar. They are undoubtedly referable to Rhabdophis helleri. We have not examined specimens mentioned by Liu et al. (2021) but we have no reason to not follow these authors. Thus it seems that the ranges of both species came very close to each other in the southern part of mainland Myanmar.

A long confusion: The southern limit of the range of the subspecies $R$. s. helleri auctorum has proven to be controversial. Bourret (1936) included only "Yunnan, Tonkin, Kwang si, Kwang tung, and Fukien", i.e., China (provinces of Yunnan, Guangxi, Guangdong, and Fujian) and North Vietnam in the range of Rhabdophis subminiatus helleri. Smith (1943) tentatively placed the southern limit of the range of this taxon at "latitude $22^{\circ} \mathrm{N}$ ", so approximately on a line connecting Mandalay in Myanmar to Hong Kong in China, in stating " $N$. s. helleri does not range south of this line, but $N$. s. subminiata often occurs north of it". In contrast, Das (2010) greatly expanded the range of $R$. $s$. helleri southwards in including herein populations of Myanmar, the whole of the Indochinese Peninsula, and Thailand, and restricted the range of the nominative subspecies to Peninsular Malaysia, Singapore and the Indo-Malayan Archipelago (Sumatra, Borneo and Java), plus the Indonesian islands of Sulawesi and Ternate.

Such a discrepancy in the definition of the recognized species in fact depends on the choice of the diagnostic characters recognized by the authors. For example, Bourret (1936) mainly based the recognition of the two subspecies on the number of ventral plates: $132-162$ ( R. $s$. subminiatus) vs. $163-179$ (R. s. helleri). Subsequently, Smith (1943), in explicitly excluding Indo-Malayan populations, based the recognition of the two subspecies upon the following characters (in the order: "subminiatus" / helleri) as follows: (1) VEN 144-164 / VEN 157-173; (2) body with a distinct pattern of black and yellow reticulations and neck tinged with vermilion-red / adults in part almost uniform in coloration; (3) subocular bar usually very distinct / subocular bar indistinct or absent; (4) nuchal groove and enlarged nuchal scales not conspicuous or even absent in the southern part of the distribution range / nuchal groove and enlarged paired scales always distinct; and (5) belly yellowish, sometimes with a black dot on the outer end of each ventral shield / belly powdered with grey. In so doing, both Bourret (1936) and Smith (1943) referred all populations of the species range to the subspecies subminiatus, except the northernmost ones. In other words, both authors combined the species $R$. subminiatus and $R$. siamensis, as recognized here. Bourret (1936) even stated that Indochinese specimens should be referred to the "variety" siamensis of Mell. Most subsequent authors followed this scheme of two subspecies.

In contrast, Das (2010) defined the two subspecies based upon the three following characters (in the order: "subminiatus" / helleri) as follows: (1) VEN 132-157 / VEN 160-172; (2) nuchal groove indistinct or absent / nuchal groove distinct; and (3) nuchal scales not enlarged / nuchal scales enlarged. Therefore, Das (2010) combined the species $R$. siamensis and $R$. helleri. However, he did not take into account the difference of the ventral pattern between $R$. helleri, that has a powdered venter, and $R$. subminiatus and $R$. siamensis, in which the venter is more or less uniform. Das (2010) also overlooked the difference in the shape of the subocular streak, as well as more subjective characters as the difference in the structure of the nuchal groove and the presence of enlarged nuchal scales between Indo-Malayan and Indochinese populations. So, depending on which character(s) various authors have considered dominant, they recognized a widespread "southern form" and a small-ranging "northern form" or vice-versa. The presence of a third species in the Asian mainland combining various characters of both forms with its own diagnostic character, the triangular subocular streak, explains this long- standing confusion.

As strange as it may be, no author has ever discussed differences in the shape of the subocular streak between Indo-Malayan 
populations, $R$. subminiatus sensu stricto, and the Indochinese ones here referred to $R$. siamensis. The shape of the subocular streak is a constant character of which exceptions, such as the presence of a triangle-shaped streak in $R$. subminiatus sensu stricto, is of very rare occurrence.

Smith (1943) and Taylor (1965) stated that adult specimens of $R$. helleri "may be almost uniform in coloration". This is especially true in the posterior part of the body that is often nearly uniform, in contrast to the body of $R$. siamensis. However, some authors pointed out that the presence of the vermilion-red hue on the neck could be useful to separate $R$. helleri from the complex $R$. subminiatus $+R$. siamensis. As explained above in the definition of species diagnostic characters, Smith's statement does not apply to the red hue covering the upper and sides of the neck. This red hue is usually conspicuous in $R$. helleri, even if it may be reduced to a small part of the scales interstitial skin and, thus, seem to be subdued. Furthermore, this red hue disappears in long-preserved specimens and turns into cream and pale yellow. In contrast, this red coloration of the neck is nearly absent in living or fresh specimens here referred to Rhabdophis confusus sp. nov. from Hainan Island (China).

The paraphyly of the genus Rhabdophis: Takeuchi et al. (2018) showed that the genus Rhabdophis Fitzinger (1843) is paraphyletic. These authors especially pointed out that the genus may be divided into a clade containing species with nuchal or nucho-dorsal glands, and another one in which referred species are devoid of such glands. As the type species of the genus Rhabdophis is Tropidonotus subminiatus Schlegel by original designation, the nomen Rhabdophis should be retained for species possessing such glands should this genus, as currently recognized, be divided on this basis.

\section{Conclusion}

The redefinition of Rhabdophis subminiatus, the resurrection of Rhabdophis siamensis, the elevation of the taxon Rhabdophis subminiatus helleri at species level and the description of Rhabdophis confusus sp. nov. modify the list of snake species of several countries, in respect to the combinations previously used in recent literature. We list these modifications in Table 3.

These four Rhabdophis species can be identified by the following dichotomous key:
1. (a) Nuchal groove well visible; $2-8$ nuchal scales enlarged, paired and aligned on each side of the groove; position of the dorsal reduction from 19 to $17 \mathrm{DSR}$ at least on the $75^{\text {th }}$ ventral plate ..... 2

(b) Nuchal groove absent (exceptionally a shallow groove barely visible); nuchal scales not enlarged (exceptionally slightly enlarged); position of the dorsal reduction from 19 to 17 DSR at most on the $75^{\text {th }}$ ventral plate

R. subminiatus

2. (a) Venter with an uniform pale background, with only the tips of ventral plates dark; at most 158 ventral plates 3

(b) Venter heavily powdered with numerous dark dots; at least 157 ventral plates R. helleri

3. (a) Subocular streak conspicuous, shaped as a broad, solid (rarely faint) black triangular fin directed backwards; widespread in the Indochinese Region ...................... R. siamensis

(b) Subocular streak completely absent; endemic to Hainan Island ................. R. confusus sp. nov.

Table 3. Current applicable names of former Rhabdophis subminiatus species complex for each country; $-=$ not reported

\begin{tabular}{|c|c|c|}
\hline \multirow{2}{*}{ Country } & \multicolumn{2}{|c|}{ Previous identification } \\
\hline & R. s. subminiatus & R. s. helleri \\
\hline Bangladesh & - & R. helleri \\
\hline Bhutan & - & R. helleri \\
\hline Cambodia & R. siamensis & - \\
\hline $\begin{array}{l}\text { China } \\
\text { (mainland) }\end{array}$ & - & R. helleri \\
\hline $\begin{array}{l}\text { China } \\
\text { (Hainan Is.) }\end{array}$ & - & $\begin{array}{l}\text { R. confusus } \\
\text { sp. nov. }\end{array}$ \\
\hline India & - & R. helleri \\
\hline Indonesia & R. subminiatus & - \\
\hline Laos & R. siamensis & R. helleri \\
\hline Malaysia & R. siamensis & - \\
\hline Myanmar & R. siamensis & R. helleri \\
\hline Nepal & - & R. helleri \\
\hline Thailand & R. siamensis & R. helleri \\
\hline Vietnam & R. siamensis & R. helleri \\
\hline
\end{tabular}

The global range of the complex of Rhabdophis subminiatus is quite similar to the ranges occupied by several species or complexes of species of Southeast Asian snakes which inhabit the Indochinese Peninsula and the isthmus of Kra, as well as Java and extending eastwards in some cases but that are not present in the Peninsular Malaysia and Borneo, and for some of them, a large part of Sumatra. In this group, we include Trimeresurus albolabris 
(Gray) (see David \& Vogel 2000) and Daboia siamensis Smith (see Wüster et al. 1992).

Another point bears on the intraspecific systematics of wide-ranging species of which the type locality is the island of Java. In this paper, we showed that populations of the complex of Rhabdophis subminiatus present north of the Indo-Malayan Region, i.e., in the Indochinese Peninsula, belong to other taxa distinct at species level. We have met a similar situation in Cylindrophis ruffus (see Amarasinghe et al. 2015). In the genus Fowlea Theobald, recently resurrected from the genus Xenochrophis Günther, we also have a similar situation: F. melanzostus (Gravenhorst) is distributed in Java and Sumatra, and is replaced by $F$. flavipuctatus (Hallowell) in the north and east and by $F$. piscator (Schneider) in the north and west (Vogel \& David 2012).

Following this new insight on the peculiarities of the Indonesian snake fauna, it might prove necessary to investigate the intraspecific systematics of wide-ranging species such as Xenopeltis unicolor $\mathrm{H}$. Boie in F. Boie; Calamaria pavimentata Duméril, Bibron \& Duméril; Ahaetulla prasina (H. Boie in $\mathrm{F}$. Boie); Ptyas korros (Schlegel); Ptyas mucosa (Linnaeus); Amphiesma stolatum (Linnaeus); Bungarus fasciatus (Schneider); Coelognathus radiatus (H. Boie in F. Boie); Rhabdophis chrysargos (Schlegel); Ophiophagus hannah (Cantor); and Python bivittatus Kuhl; If "northern" populations of these wide-ranging species, namely those inhabiting the Indochinese or Indo-Himalayan continental Regions, prove to be distinct at species level from the "southern" insular ones of the Indo-Malayan Region, the specificity of this latter region will have to be re-evaluated and the biogeographical gap of the Isthmus of Kra, already pointed out by Pauwels et al. (2003), will be reinforced.

\section{Acknowledgements}

We sincerely thank Sjon Hauser (Chiang Mai, Thailand), Kurt Orion (Kuala Lumpur, Malaysia), Jin-Long Ren (Chengdu, China), Hans H. Schleich (München, Germany), Alexandre Teynié (Aubière, France), Frank Tillack (Berlin, Germany), and Jigme T. Wangyal (Trashigang, Bhutan) for their assistance and for having readily shared their data on specimens that they collected or examined and for having provided us useful photographs. We are indebted to Akira Mori (Kyoto, Japan) and Hirohiko Takeuchi
(Kanagawa, Japan) who communicated us their data on specimens used in Takeuchi et al.'s (2018) phylogeny, and Kaushik Deuti (Kolkata, India) for his assistance with rare Indian literature. Hermann H. Schleich helped us with unpublished data on the specimen from Nepal depicted in his book. Parinya Pawangkhanant is acknowledged for the contribution of pictures of $R$. siamensis; W. Scott Lupien for the contribution of pictures of the new species here described. We are also grateful to Colin J. McCarthy and Patrick Campbell (NHMUK), Robert C. Drewes and Jens V. Vindum (CAS), Alan Resetar (FMNH), Hmar T. Lalremsanga (HT), Ivan Ineich, Nicolas Vidal and Annemarie Ohler (MNHN), Silke Schweiger and Georg Gassner (NMW), Pim Arntzen and Esther Dondorp (RMNH), Saibal Sengupta (S), Dennis Rödder and Wolfgang Böhme (ZFMK) and Mark-Oliver Rödel and Frank Tillack (ZMB) for the possibility that they offered us to examine specimens deposited in the collections of their respective institutions. Finally, we would like to thank Vivek Cyriac, Ivan Ineich (MNHN), A.A. Thasun Amarasinghe (Universitas Indonesia), and two anonymous reviewers for their review and additions to this manuscript.

\section{Literature cited}

Ahmad, F., S.M.I. Alam, and M.A.R. Sarker (2015). Geographic distribution: Rhabdophis subminiatus (Red-necked Keelback Snake). Herpetological Review, 46(4): 576.

Ahmed, M.F, A. Das, and S.K. Dutta (2009). Amphibians and Reptiles of Northeast India: A photographic guide. Aaranyak, Guwahati (Assam): 169pp.

Amarasinghe, A.A.T., P.D. Campbell, J. Hallermann et al. (2015). Two new species of the genus Cylindrophis Wagler, 1828 (Squamata: Cylindrophiidae) from Southeast Asia. Amphibian \& Reptile Conservation, 9(1): 34-51.

Barbour, T. (1912). A contribution to the zoögeography of the East Indian islands. Memoirs of the Museum of Comparative Zoölogy at Harvard College, 44(1): 1-203.

Bhattarai S, Pokheral CP, Lamichhane BR, Regmi UR, Ram AK Sudebi N (2018). Amphibians and reptiles of Parsa National Park, Nepal. Amphibian \& Reptile Conservation, 12(1): 3548.

Boulenger, G.A. (1893a). Catalogue of the Snakes in the British Museum (Natural History). Volume I., containing the families Typhlopidae, Glauconiidae, Boidae, Ilysiidae, 
Uropeltidae, Xenopeltidae and Colubridae Aglyphae, part. British Museum (Natural History), London: 448pp.

Boulenger, G.A. (1893b). Viaggio di Leonardo Fea in Birmania e regioni vicine. LII. Concluding report on the Reptiles and Batrachians obtained in Burma by Signor L. Fea, dealing with the collection made in Pegu and the Karin Hills in 1887-1888. Annali del Museo Civico di Storia Naturale di Genova 2, 13(33): 304347.

Boundy, J. (2020). Snakes of the World: A Supplement. CRC Press, Boca Raton, London $\&$ New York: 273pp.

Bourret, R. (1934). Notes herpétologiques sur l'Indochine française. III. Ophidiens d'Annam et du Moyen Laos. Bulletin Général de l'Instruction Publique, Hanoi, $13^{e}$ Année (1933-1934): 167-176. [separate, 3-12].

Bourret, R. (1936). Les Serpents de l'Indochine. Tome II. Catalogue systématique descriptif. Henri Basuyau et Cie, Toulouse: 505pp.

Bulian, J. (1999). Über die Schlangenfauna eines Gartens in Südthailand. Elaphe, 7(4): 61-67.

Campden-Main, S.M. (1970). A Field Guide to the Snakes of South Vietnam. Smithsonian Institution, Washington: $112 \mathrm{pp}$.

Chan-ard, T., W. Grossmann, A. Gumprecht, and K-D. Schulz (1999). Amphibians and Reptiles of Peninsular Malaysia and Thailand: An illustrated checklist [Amphibien und Reptilien der Halbinsel Malaysia und Thailands. Eine illustrierte Checkliste]. Bushmaster Publications, Würselen: 240pp.

Chan-ard, T., J.W.K. Parr, and J. Nabhitabhata (2015). A Field Guide to the Reptiles of Thailand. Oxford University Press, New York: 314pp.

Charlton, T. (2019 [“2020”]). A Guide to Snakes of Peninsular Malaysia and Singapore. Natural History Publications (Borneo), Kota Kinabalu: 299pp.

Cox, M.J. (1991). The Snakes of Thailand and their Husbandry. Krieger Publishing Co., Malabar (Florida): 526pp.

Cox, M.J., M.F. Hoover, L. Chanhome, and K. Thirakhupt (2012). The Snakes of Thailand. Chulalongkorn University Museum of Natural History, Bangkok: 844pp.

Cox, M.J., P.P. van Dijk, J. Nabhitabhata, and K. Thirakhupt (1998). A Photographic Guide to Snake and other Reptiles of Peninsular Malaysia, Singapore and Thailand. Ralph Curtis Books, Sanibel Island (Florida): 144pp.

Currin, C. (2016). Recent reptiles records from Kaeng Krachan National Park, Thailand. Southeast Asia Vertebrate Records: 117-120.
Das, I. (2002). A Photographic Guide to Snakes and other Reptiles of India. New Holland Publishers (UK) Ltd, London: 144pp.

Das, I. (2006). A Photographic Guide to Snakes and other Reptiles of Borneo. New Holland Publishers (UK) Ltd, London: 144pp.

Das, I. (2010). A Field Guide to the Reptiles of Southeast Asia. New Holland Publishers (UK) Ltd, London: 376pp.

Das, I. (2012). A Naturalist's Guide to the Snakes of Southeast Asia. John Beaufroy Publishing, Oxford (UK): 160pp.

Das, I. (2018). A Naturalist's Guide to the Snakes of Southeast Asia. $2^{\text {nd }}$ ed., John Beaufroy Publishing, Oxford (UK): 176pp.

Das. I. and A. Das (2017). A naturalist's Guide to the Reptiles of India, Bangladesh, Bhutan, Nepal, Pakistan and Sri Lanka. John Beaufoy Publishing Ltd., Oxford (UK): 176pp.

David, P., I. Agarwal, R. Athreya, R. Mathew, G. Vogel, A. Mistry (2015a). Revalidation of Natrix clerki Wall, 1925, an overlooked species in the genus Amphiesma Duméril, Bibron \& Duméril, 1854 (Squamata: Natricidae). Zootaxa, 3919(2): 375-395.

David, P., O.S.G. Pauwels, T.Q. Nguyen, G. Vogel (2015b). On the taxonomic status of the Thai endemic freshwater snake Parahelicops boonsongi, with the erection of a new genus (Squamata: Natricidae). Zootaxa, 3948(2): 203-217.

David, P. and G. Vogel (1996). The Snakes of Sumatra: An Annotated Checklist and Key with Natural History Notes. Edition Chimaira, Frankfurt-am-Main: 260pp.

David, P. and G. Vogel (2000). On the occurrence of Trimeresurus albolabris (Gray, 1842) on Sumatra Island, Indonesia (Reptilia, Serpentes, Viperidae, Crotalinae). Senckenbergiana Biologica, 80(1\&2): 225-232.

de Lang, R. (2017). The Snakes of Java, Bali and Surrounding Islands. Edition Chimaira, Frankfurt am Main: 435pp.

de Lang, R. and G. Vogel (2005). The Snakes of Sulawesi: A Field Guide to the Land Snakes of Sulawesi with Identification Keys. Edition Chimaira, Frankfurt am Main: 312 pp.

De Rooij, N. (1917). The reptiles of the IndoAustralian Archipelago. II. Ophidia. E.J. Brill, Leyden: 334pp.

Deuve, J. (1961a). Observations sur les serpents du Laos, avec description d'une variété nouvelle. Bulletin du Muséum National d'Histoire Naturelle 2, 32(5): 376-379.

Deuve, J. (1961b). Liste annotée des serpents du Laos. Bulletin de la Société royale des Sciences naturelles du Laos, 1: 5-32. 
Deuve, J. (1970). Serpents du Laos. Mémoires ORSTOM Paris, 39: 1-251.

Doria, G., M. Petri, A. Bellati et al. (2013). Rhabdophis in the Museum of Genova with description and molecular analysis of a new species from Sumatra (Reptilia, Serpentes, Colubridae, Natricinae). Annali del Museo Civico di Storia Naturale "G. Doria”, 105: 139-153.

Dowling, H.G. (1951). A proposed standard system of counting ventrals in snakes. British Journal of Herpetology, 1(5): 97-99.

Duméril, A.M.C.., G. Bibron, A.H.A. Duméril (1854). Erpétologie générale ou histoire naturelle complète des reptiles. Tome septième. Première partie, comprenant l'histoire des serpents non venimeux. Paris, Librairie Encyclopédique de Roret: 780pp.

Dunn, E.R. (1927). Results of the Douglas Burden Expedition to the Island of Komodo. II. Snakes from the East Indies. American Museum Novitates, 287: 1-7.

Fitzinger, L.J.F.J. (1843). Systema reptilium. Fasciculus primus. Amblyglossae. Braumüller \& Seidel Bibliopolas, Vindobonae [Vienna]: 106pp.

Günther, A.C.L.G. (1858). Catalogue of Colubrine Snakes in the Collection of the British Museum. British Museum, London: $281 \mathrm{pp}$.

Günther, A.C.L.G. (1864). The Reptiles of British India. Ray Society, London: 452pp.

Günther, A.C.L.G. (1873). Notes on some reptiles and batrachians obtained by Dr. Adolf Bernhard Meyer in Celebes and the Philippine Islands. Proceedings of the Zoological Society of London, 1873(1): 165-172.

Hasan, M.K., M.M. Khan, and M.M. Feeroz (2014). Amphibians and Reptiles of Bangladesh: A Field Guide. Arannayk Fondation, Dhaka: 191pp.

Hecht, V.L., C.T. Pham, T.T. Nguyen et al. (2013). First report on the herpetofauna of Tay Yen Tu Nature Reserve, northeastern Vietnam. Biodiversity Journal, 4(4): 507-552.

$\mathrm{Hu}$, B., M. Huang, Z. Xie et al. (1980). Iconography of Chinese Snakes [In Chinese]. Shanghai Sciences \& Technology Press, Shanghai: $167 \mathrm{pp}$.

Iskandar, D.T. and W.R. Erdelen (2006). Conservation of amphibians and reptiles in Indonesia: issues and problems. Amphibian \& Reptile Conservation, 4(1): 60-87.

Jan, G. and F. Sordelli (1868). Iconographie générale des ophidiens. J.-B. Baillière \& Fils, Paris, Tome Second, Livraison 29, Pl. I-VI.

Jestrzemski, D., S. Schütz, T.Q. Nguyen, and T. Ziegler (2013). A survey of amphibians and reptiles in Chu Mom Ray National Park, Vietnam, with implications for herpetofaunal conservation. Asian Journal of Conservation Biology, 2(2): 88-110.

Kamruzzaman, M. (2009). Genus Rhabdophis Fitzinger, 1843. Pp. 147-148. In: Kabir, S.M.H., M. Ahmad, A.T.A. Ahmed et al. (eds.). Asiatic Encyclopedia of Flora and Fauna of Bangladesh, Vol. 25. Asiatic Society of Bangladesh, Dhaka.

Kamsi, M., S. Handayani, A.J. Siregar, and G. Fredriksson (2017). Buku Panduan Lapangan Amfibi Reptil Kawasan Hutan Batang Toru. Yayasan Ekosistem Lestari, Medan (Indonesia): 307 pp.

Karsen, S.J., M.W-n. Lau, and A. Bogadek (1986). Hong Kong Amphibians and Reptiles. Urban Council, Hong Kong: 136 pp.

Karsen, S.J., M.W-n. Lau, and A. Bogadek (1998). Hong Kong Amphibians and Reptiles, $2^{\text {nd }}$ ed., Provisional Urban Council, Hong Kong: $186 \mathrm{pp}$.

Kästle, W., K. Rai, and H.H. Schleich (2013). Field Guide to Amphibians and Reptiles of Nepal. ARCO-Nepal: 609pp.

Koushik [Bhattacharjee, K.] 2015. Saap. Naturism, Kolkata: 157 pp.

Kurniati, H. (2003). Amphibians and Reptiles of Gunung Halimun National Park West Java, Indonesia (frogs, lizards and snakes). Research Center for Biology-LIPI, Cibinong (Indonesia): 134pp.

Lalremsanga, H.T. and S. Lalronunga (2017). Mizoram Rûl Manchin. Biodiversity and Nature Conservation Network Aizawl \& Mizoram Science, Technology \& Innovation Council Aizawl (Mizoram): 132pp.

Li, Z. (2011). Amphibians and Reptiles of Guangdong [in Chinese]. Guangdong Science and Technology Press, Guangzhou: 266pp.

Lim, F.L.K. and M.T-M. Lee (1989). Fascinating Snakes of Southeast Asia: An Introduction. Tropical Press Sdn. Bhd., Kuala Lumpur: 124pp.

Lim, K.K.P. and F.L.K. Lim (1992). A Guide to the Amphibians and Reptiles of Singapore. Singapore Science Centre, Singapore: 160pp.

Lim, K.K.P. and F.L.K. Lim (2002). A Guide to the Amphibians and Reptiles of Singapore. Revised Edition. Singapore Science Centre, Singapore: $160 \mathrm{pp}$.

Liu, Q., X. Xie, Y. Wu et al. (2021). High genetic divergence but low morphological differences in a keelback snake Rhabdophis subminiatus (Reptilia, Colubridae). Journal of Zoological Systematics \& Evolutionary Research, 59: 1371-1381. 
Lönnberg, E. (1899). On a small collection of Javanese reptiles containing a new species of snakes. Zoologischer Anzeiger, 22(581): 108111.

Majumder, J., P.P. Bhattacharjee, K. Majumdar et al. (2012). Documentation of herpetofaunal species richness in Tripura, northeast India. NeBIO, 3(1): 60-70.

Malnate, E.V. (1960). Systematic division and evolution of the colubrid snake genus Natrix, with comments on the subfamily Natricinae. Proceedings of the Academy of Natural Sciences of Philadelphia, 112(3): 41-71.

Malnate, E.V. and G. Underwood (1988). Australasian natricine snakes of the genus Tropidonophis. Proceedings of the Academy of Natural Sciences of Philadelphia, 140(1): 59201.

Manthey, U. and W. Grossmann (1997). Amphibien \& Reptilien Südostasiens. Natur und Tier-Verlag, Münster: 512pp.

Maradjo, M. (1976). Ular: Jilid 1. Pp. 1-31. In: Fauna Indonesia. PT. Karya Nusantara, Jakarta.

Marlon, R. (2014). Panduan Visual dan Identifikasi Lapangan: 107+ Ular Indonesia. Indonesia Nature and Wildlife Publishing, Jakarta: 251pp.

Mell, R. (1931). List of Chinese snakes. Lingnan Science Journal, 8 [1929]: 199-219.

Messenger, K.R., D. Rosenberg, K.K. Caldwell, and W.L. Sargent (2012). Rhabdophis subminiatus helleri (red-necked keelback) defensive behavior. Herpetological Review, 43(3): 497.

Nabhitabhata, J., T. Chan-ard, and Y. Chuaynkern (2004). Checklist of Amphibians and Reptiles in Thailand. Office of Environmental Policy and Planning (OEPP), Bangkok, Biodiversity Series, 9 [2000]: 152pp.

Nemes, L., R. Babb, W. van Devender et al. (2013). First contribution to the reptile fauna of Quang Ngai Province, central Vietnam. Biodiversity Journal, 4(2): 301-326.

Nguyen, S.V., C.T. Hô, and T.Q. Nguyen (2009). Herpetofauna of Vietnam. Edition Chimaira, Frankfurt am Main: 768pp.

Pauwels, O.S.G., P. David, C. Chimsunchart, and K. Thirakhupt (2003). Reptiles of Phetchaburi Province, Western Thailand: a list of species, with natural history notes, and a discussion on the biogeography at the Isthmus of Kra. Natural History Journal of Chulalongkorn University, 3(1): 23-53.

Piao, Y.G., Z.N. Chen, Y.Q. Wu et al. (2020). A new species of the genus Rhabdophis Fitzinger, 1843 (Squamata: Colubridae) in
Southwestern Sichuan, China. Asian Herpetological Research, 11(2): 95-107.

Pope, C.H. (1935). The Reptiles of China. American Museum of Natural History, New York: 604pp.

Purkayastha, J. (2012). Urban Herpetofauna: Amphibians and Reptiles of Guwahati. A pictorial guide. Students' Stores, Guwahati (Assam): 53pp.

Purkayastha, J. (2013). An amateur's guide to Reptiles of Assam. EBH Publishers, Guwahati (Assam): 146pp.

Purkayastha, J. (2018). Urban biodiversity: an insight into the terrestrial vertebrate diversity of Guwahati, India. Journal of Threatened Taxa, 10(10): 12299-12316.

Purkayastha, J., M. Das, and S. Sengupta (2011). Urban herpetofauna: a case study in Guwahati City of Assam, India. Herpetology Notes, 4: 195-202.

Qi, S. (2019). A Photographic Guide to Reptiles of China. Chongqing University Press, Chongqing: 218pp.

Reitinger, F.F. (1978). Common Snakes of Southeast Asia and Hong Kong. Heinemann Educational Books (Asia) Ltd., Hong Kong: 114 pp.

Rendahl, H. (1937). Beiträge zur Herpetologie von Birma. Arkiv för Zoologi Stockholm, 29(10): $1-29$.

Romer, J.D. (1979a). Second revised annotated checklist with keys to the Snakes of Hong Kong. Memoirs of the Hong Kong Natural History Society, 14: 1-23.

Romer, J.D. (1979b). The red-necked keelback, a venomous snake of Hong Kong. Urban Council, Hong Kong: 5pp.

Romer, J.D. (1983). Illustrated Guide to the Venomous Snakes of Hong Kong. Urban Council, Hong Kong: 11pp.

Rusli, N. (2016). Mengenal Ular Jabodetabek (Snakes of Jakarta and its surroundings). Ciliwung Reptile Center Bogor \& Bypass Bogor: 168pp.

Saint Girons, H. (1972). Les serpents du Cambodge. Mémoires du Muséum national d'Histoire naturelle (Nouvelle série), 74: 1170.

Schlegel, H. (1826a). Notice sur l'erpétologie de l'Ile de Java; par M. Boïé (Ouvrage manuscrit). Bulletin des Sciences naturelles et de Géologie (Section II du Bulletin Universel des Sciences naturelles de Férussac) Paris, 9(2): 233-240.

Schlegel, H. (1826b). Erpetologische Nachrichten. Isis von Oken, 20(3): 281-294. 
Schlegel, H. (1837). Essai sur la physionomie des serpens. II. Partie descriptive. J. Kips, H. Hz, W. P. Van Stockhum, The Hague: 606pp.

Schleich, H.H. and W. Kästle (eds.) (2002). Amphibians and Reptiles of Nepal. A.R.G. Gantner Verlag K.G, Ruggell (Liechtenstein): 1201pp.

Schmidt, K.P. (1925). New reptiles and a new salamander from China. American Museum Novitates, 157: 1-5.

Schmidt, K.P. (1927a). The Reptiles of Hainan, with abstracts from the field notes of Clifford H. Pope. Bulletin of the American Museum of Natural History, 54(3): 395-465.

Schmidt, K.P. (1927b). Notes on Chinese Reptiles. Bulletin of the American Museum of Natural History, 54(4): 467-551.

Seba, A. (1735). Locupletissimi Rerum Naturalium Thesauri Accurata Descriptio, et Iconibus Artificiosissimus Expressio, per Universam Physices Historiam. Opus, cui, in hoc Rerum Genere, Nullum Par Existit. Ex Toto Terrarum Orbe Collegit, Digessit, Descripsit, et Depingendum Curavit. Tomus II. JanssonioWaesbergios, J. Wetstenium \& Gul. Smith, Amstelaedami [Amsterdam]: 154pp.

Shah, K.B. and S. Tiwari (2004). Herpetofauna of Nepal: A Conservation Companion. IUCN The World Conservation Union, Kathmandu: 237pp.

Shalauddin, M., O. Shahadat, M.U.H. Khatun (2019). Rhabdophis subminiatus (red-necked keelback) diet. Herpetological Review, 50(2): 401.

Sharma, S.K., D.P. Pandey, K.B. Shah et al. (2013). Venomous Snakes of Nepal. B.P. Koirala Institute of Health Sciences, Dharan (Nepal): 76pp.

Shi, H., E. Zhao, and L. Wang (2011). The Amphibian and Reptile Fauna of Hainan [in Chinese], Science Press, Beijing: 285pp.

Siegel, S. (1956). Nonparametric Statistics for the Behavioral Sciences. McGraw-Hill Kogakusha, New York: 312pp.

Smith, M.A. (1930). The Reptilia and Amphibia of the Malay Peninsula from the Isthmus of Kra to Singapore (A supplement to Dr. G. A. Boulenger's Reptilia and Batrachia, 1912). Bulletin of the Raffles Museum, 3: 149.

Smith, M.A. (1943). The Fauna of British India, Ceylon and Burma, including the whole of the Indo-Chinese Sub-region. Reptilia and Amphibia, Vol. III: Serpentes. Taylor \& Francis, London: 583 pp.

Stuebing, R.B. (1991). A checklist of the snakes of Borneo. Raffles Bulletin of Zoology, 39 (2): 323-362.
Stuebing, R.B. and R.F. Inger (1999). A Field Guide to the Snakes of Borneo. Natural History Publications (Borneo), Kota Kinabalu (Malaysia): 254pp.

Stuebing, R.B., R.F. Inger, and B. Lardner (2014). A Field Guide to the Snakes of Borneo, $2^{\text {nd }} \mathrm{Ed}$. Natural History Publications (Borneo), Kota Kinabalu (Malaysia): 310pp.

Suhono, B. (1986). Ular-ular berbisa di Jawa. Penerbit Antar Kota, Jakarta: 109pp.

Sworder, G.H. (1924). An addition to the list of Singapore Snakes and a few notes on species already included. The Singapore Naturalist, 3: 21-22.

Takeuchi, H., A.H. Savitzky, L. Ding et al. (2018). Evolution of nuchal glands, unusual defensive organs of Asian natricine snakes (Serpentes: Colubridae), inferred from a molecular phylogeny. Ecology \& Evolution, 8(20): 10219-10232.

Taylor, E.H. (1965). The serpents of Thailand and adjacent waters. University of Kansas Science Bulletin, 45(9): 609-1096.

Taylor, E.H. and R.E. Elbel (1958). Contribution to the herpetology of Thailand. University of Kansas Science Bulletin, 38(2): 1033-1189.

Teo, R.C.H. and S. Rajathurai (1997). Mammals, reptiles and amphibians in the nature reserves of Singapore: diversity, abundance and distribution. Gardens' Bulletin Singapore, 49: 353-425.

Teynié, A. and P. David (2010). Voyages naturalistes au Laos. Les Reptiles. Éditions Revoir, Nohanent (France): 315pp.

Tweedie, M.W.F. (1954). The Snakes of Malaya. Government Printing Office, Singapore: 139pp.

Tweedie, M.W.F. (1983). The snakes of Malaya. $3^{\text {rd }}$ Ed., Singapore National Printers, Singapore: $167 \mathrm{pp}$.

van Hoesel, J.K.P. (1959). Ophidia Javanica. Museum Zoologicum Bogoriense, Bogor, Indonesia: 188pp.

Vassilieva, A.B., E.A. Galoyan, N.A. Poyarkov, and P. Geissler (2016). A photographic Field Guide to the Amphibians and Reptiles of the Lowland Monsoon Forests of Southern Vietnam. Edition Chimaira, Frankfurt-amMain: 324 pp.

Vogel, G. and P. David (2012). A revision of the Xenochrophis piscator species group (Squamata: Natricidae). Zootaxa, 3473: 1-60.

Wall, F. (1923). How to Identify the Snakes of India, including Burma and Ceylon. Printed by author, Karachi: 56pp. 
Wall, F. (1925). A new Snake from Burma. Journal of the Bombay Natural History Society, 30(4): 734.

Wallach, V., K.L. Williams, and J. Boundy (2014). Snakes of the World: A Catalogue of Living and Extinct Species. CRC Press, Boca Raton (Florida): 1209pp.

Wang, K., J. Ren, H. Chen et al. (2020). The updated checklists of amphibians and reptiles of China. Biodiversity Science, 28(2), 189218.

Wangyal, J.T. (2019). The status of herpetofauna of Bhutan. Journal of Bhutan Ecological Society, 1: 20-39.

Whitaker, R. and A. Captain (2004). Snakes of India. Draco Books, Chennai: 479pp.

Wu, L., D.J. Li, and J.S. Liu (1985). Reptilian Fauna of Guizhou [in Chinese]. Guizhou People Press, Guiyang: 436pp.

Wüster, W., S. Otsuka, A. Malhotra, and R.S. Thorpe (1992). Population systematics of Russell's viper: A multivariate study. Biological Journal of the Linnean Society, 47(1): 97-113.

Yang, D. and D. Rao (eds.) (2008). Amphibia and Reptilia of Yunnan [in Chinese]. Yunnan Publishing Group Corporation \& Yunnan Science and Technology Press, Kunming (Yunnan): 411pp.
Zhang, Y. (2009). Herpetology in Guangxi [in Chinese]. Guangxi Normal University Press, Guilin (Guangxi): 170pp.

Zhao, E. (2006). Snakes of China [in Chinese]. Anhui Science and Technology Publishing House Publishing, Hefei (Anhui Province): 372pp (volume I), 279pp (volume II).

Zhao, E. and K. Adler (1993). Herpetology of China. Society for the Study of Amphibians and Reptiles, Oxford (Ohio): 522 pp.

Zhao, E. and Q. Huang (eds.) (2003). Coloured Atlas of Sichuan Reptiles. Chinese Forestry Press, Beijing: 292pp.

Zhao, E., M. Huang, Y. Zong et al. (eds.) (1998). Fauna Sinica [in Chinese]. Reptilia Vol. 3: Squamata Serpentes. Science Press, Beijing: 522 pp.

Ziegler, T. (2002). Die Amphibien und Reptilien eines Tieflandfeuchtwald-Schutzgebietes in Vietnam. Natur und Tier- Verlag GmbH, Münster: $342 \mathrm{pp}$.

Ziegler, T., A. Rauhaus, T.D. Tran et al. (2015). Die Amphibien- und Reptilienfauna der MeLinh-Biodiversitätsstation in Nordvietnam. Sauria, 37(4): 11-44.

Zug, G.R. and D.G. Mulcahy (2019). Identification guide Amphibians and reptiles of South Tanintharyi. Fauna \& Flora International, Myanmar Programme: 102pp.

\section{Appendix. Specimens Examined}

Rhabdophis subminiatus (46 ex.): Indonesia: Java: RMNH 1067 (lectotype of Tropidonotus subminiatus), RMNH 1061 (paralectotype), RMNH 1063 (paralectotype), RMNH 1066 (paralectotype), MNHN-RA 0223, MNHN-RA 0223A-B, MNHN-RA 0225, MNHN-RA 1905.00880089, MNHN-RA 1906.0022, NMW 22467:2, NMW 22467:5-7, "Batavia", now Jakarta, Special Capital Region of Jakarta; MNHN-RA 0226, MNHN 1911.0168-0169, MNHN 1911.0171, MNHN 1975.0102, NMW 22458:2-22458:3, ZFMK 33447, ZMB 28363, ZMB 51797, ZMB 91796, "Java"; ZMB 14409, "Samarang", now Semarang, North Java Province; ZFMK 33448-33450, ZMB 20515, ZMB 83095-097, "Buitenzorg", now Bogor, West Java Province; ZMB 29535, "Tjibodas", now Cibodas, West Java Province; ZMB 51785, Bogor, West Java Province; Sumatra: NMW 14168, "Jehlei, Sumatra", now Medan, North Sumatra Province; NMW 22466:1-22466:4, "Deli", now Medan, North Sumatra Province; ZMB 32076, "Sumatra"; Nias Island: ZMB 517793-794; Sulawesi (?): NHMUK 1946.1.13.23 (ex BM 71.7.20.201; holotype of Tropidonotus manadensis Günther, 1873), "Manado", now Menado, North Sulawesi Province.

Rhabdophis siamensis (79 ex.). Laos: MNHN 1884.0555, MNHN 1884.0559, "Louangphabang”, now Luangphabang, Louangphabang Province; MNHN 1896.0638-0640, "Laos”, no locality; MNHN 1897.0422, "Pan Pi, près de Khou (Laos)", now Ban Pauy Khoulao, Xaignabouli Province; MNHN 1962.0282, "Ban Pong, prov. Thekkek (Laos)", now Ban Pong, Khammouan Province; MNHN 1985.0401, $4 \mathrm{~km}$ west of Vientiane, Vientiane Prefecture; MNHN 2003.3351, Sepian, Boloven Highlands, Champasak Province; MNHN 2003.3366, Kiatngong, Xepian NBCA, Champasak Province; ZFMK 47065-66, “75 km N Viengtiane, Muan”, a locality in Vientiane Province. Vietnam: FMNH 252155, FMNH 252157, Ankhe District, Gia Lai Province; FMNH 262196, "Dong Nai", now Dong Nai Province; MNHN A830, MNHN 1894.1109-1111, MNHN 1912.0068, "Annam"; MNHN 1894.0477, “Annam (Pays des Moïs Bahnars”, i.e., 'Annam, land of Moi Bahnars people', now land of $\mathrm{Ba} \mathrm{Na}$ people, in provinces of Gia Lai, Kon Tum, Dak Lak, Phu Yen, and Binh Dinh; MNHN 1907.0033, "recueilli dans 1'herbe rare des mamelons Dangkia (S. Annam)", i.e., 'collected in sparse 
grasses on Dangkia Hills, South Annam', now Dankia Hills, Dalat, Lac Duong District, Lam Dong Province; MNHN 1938.0121 "Laobao", now Lao Bao, Huong Hoa District, Quang Tri Province; MNHN 1973.0140-0141, MNHN 1973.0143, "Choreo, prov. de Phu-Bôn", now Cheo Reo $\left(13^{\circ} 25^{\prime} \mathrm{N}\right.$ $\left.108^{\circ} 30^{\prime} \mathrm{E}\right)$, Gia Lai Province; MNHN 1974.1286, MNHN 1974.1287-88, MNHN 1974.1290, "Arboretum de Tran Bôm", now Arboretum of Bien Hoa, Dong Nai Province; ZFMK 94667, "Bato District, Quang Ngai Province", now Ba to District, Quang Ngai Province. Cambodia: NHMUK 60.8.28.27, no specified locality; FMNH 257243, "Cambodia, Siem Reap Prov., Bante Sre Dist.", now Banteay Srei District, Siem Reap Province; FMNH 259207-209, "Cambodia, Mondolkiri Prov, Pichrada Dist.", now Pechr Chenda, Mondulkiri Province; FMNH 263010, Siem Pang District, Stung Treng Province; FMNH 271550, Sihanoukville (or Preah Sihanouk) Province; MNHN 1970.04650470, "Cambodge", no locality; ZFMK 88330-88331, ZFMK 92640, Phnom Kulen National Park, Siem Reap Province; ZFMK 90428, Kulen Promtep Wildlife Sanctuary, Preah Vihear Province and Siem Reap Province. Thailand: NHMUK 1969.1755, "Bon Tuey, Phan Phi Say, N.E. Thailand", unidentified locality; MNHN 1885.0386, "Entre Pékim et Bangkok (Siam)", now between Prachinburi and Bangkok, Prachinburi Province; MNHN 1987.3844, Khao Chong, now a part of Khao Pu - Khao Ya National Park, Trang Province; MNHN 1990.3849, "Thaïlande”, no locality; MNHN 1997.6594, Ban Klong Khian, Takua Thung District, Phang-Nga Province; NMW 14165:1, NMW 22464:1-6, "Don-Pia-Fei (Mts)"; NMW 22465:1-4, "Don Rek", now Dângrêk Mountains, south-eastern Thailand (Buriram, Surin and Sisaket provinces); NMW 22472:1-2, NMW 22472:5, "Tschai-Pun", now Chaiyaphum, Chaiyaphum Province; NMW 22472:3-4, "Srugora", unidentified locality; ZFMK 13185, Kanchanaburi Province; ZFMK 16666, Rayong, Rayong Province; ZFMK 62528, "W Bangkok, Photaram", now Photharam, Ratchaburi Province; ZMB 30222 (Lectotype here designated), "Siam", i.e., Thailand, no locality; ZMB 57405, ZMB 58953, Khao Lak, Phang-Nga Province; ZRC 2.5381, Khlong Sa Kieu, Nan Nai Sa, Krabi Province. Myanmar: NHMUK 84.5.8.10, "Tenasserim", now Tanintharyi Region. Federation of Malaysia: West Malaysia. FMNH 178759, "Malaysia"; ZMB 51330, "Malaya". No locality: MNHN 1927.0058, "Indochine".

Rhabdophis helleri (51 ex.). India: NHMUK 53.8.17.48, "Sikkim"; NHMUK 72.4.17.338, "Himalayas", no locality; NHMUK 1907.12.16.8, "Shillong, Khasi Hills, 4,900 feet", Shillong, State of Meghalaya; NHMUK 1908.6.23.20, "Dibugarh, Assam", now Dibrugarh, State of Assam; NHMUK 1936.4.2.1, "Mal District, N-Bengal, Dooars, $4000 \mathrm{ft}$ ", now Malda District, State of West Bengal; FMNH 11802, "Bengal Presidency"; HT03 (AA1), Aizawl, State of Mizoram; NMW 22468:1-22468:3, Darjeeling, State of West Bengal; S. 0125 (Saibal Sengupta private's collection), Guwahati, State of Assam. Myanmar: NHMUK 93.6.30.1, "Nampanvet, Shan State", now Nampandet, Shan State; NHMUK 93.16.17.2, "North Chin Hills, Upper Burma"; NHMUK 1925.12.22.43-44, NHMUK 1926.3.17.1, Maymyo, Mandalay Region; NHMUK 1925.12.22.45, "Katha, N-Burma", now Katha, Katha District, Sagaing Region; NHMUK 1974.893-894, "Myitkyina, Upper Burma", Myitkyina District, Kachin State; FMNH 42677, Myitkyina District, Kachin State; MNHN 1893.0404, "Mts Carin, 1200-1300 m", now Mts. Karen, locality specified by Boulenger (1893b: 322) as "Thao, District of Karin Bia-po", now Tahò, $19^{\circ} 23^{\prime} \mathrm{N}, 9^{\circ} 54^{\prime E}$, Tauggyi District, Shan State; NMW 22470, ZMB 11623, "Carin Mts.". People's Republic of China: NHMUK 1914.3.2.10, "Wanting Chou, Yunnan", now Wanding, Wanding District, Yunnan Province; NHMUK 1940.4.26.5, "SW Yunnan", Yunnan Province; FMNH 7142, "Teng Yueh", now Tengchong, Baoshan City, Yunnan Province; MNHN 1912.0318, "Kouy Tchéou, region de Pin Fa", now region of Pingfa, Guizhou Province; FMNH 71139, New Territories, Hong Kong S. A. R.; ZMB 28425, "Canton", now Guangzhou, Guangdong Province; ZMB 38834, ZMB 38834A, "Lufao, Kwangtung", now Lubao, Guangdong Province; ZMB 67297, "Su Tin, Kwangtung", now Sudin, Guangdong Province; ZMB 67299-67303, "Lao Fao Shan, Kwantung", now Lau Fau Shan, New Territories, Hong Kong S. A. R.; Vietnam: MNHN 0081, "Lao Cai", now Lào Cai, Lào Cai Province; MNHN 1901.0508, "Yen Bay (Tonkin), now Yen Bai, Yen Bai Province; MNHN 1904.0393-94, "Bao Lac, Tonkin", now Thi Tran Bao Lac, Cao Bang Province; MNHN 1912.0068, "Tonkin", i.e., northern Vietnam; MNHN 1935.0054-58, "Chapa", now Sa Pa, Lào Cai Province. Thailand: MNHN 8552, Hui Nam Dang, 12 km north of Ban Pa Pae, Chiang Dao District, Chiang Mai Province; MNHN 1998.8550, Ban Mae Tae, $5 \mathrm{~km}$ east of Wiang Haeng, Wiang Haeng District, Chiang Mai Province. No locality: MNHN 1892.0265, "Indochine". 